\title{
Environmental and Economic Optimization Model for Electric System Planning in Ningxia, China: Inexact Stochastic Risk-Aversion Programming Approach
}

\author{
L. Ji, ${ }^{1}$ D. X. Niu, ${ }^{1}$ G. H. Huang, ${ }^{2}$ W. Li, ${ }^{3}$ and Z. P. Liu ${ }^{3}$ \\ ${ }^{1}$ Research Institute of Technology Economics Forecasting and Assessment, School of Economics and Management, \\ North China Electric Power University, Beijing 102206, China \\ ${ }^{2}$ Environmental Systems Engineering Program, Faculty of Engineering, University of Regina, Regina, SK, Canada S4S 0A2 \\ ${ }^{3}$ MOE Key Laboratory of Regional Energy Systems Optimization, SઐC Resources and Environmental Research Academy, \\ North China Electric Power University, Beijing 102206, China
}

Correspondence should be addressed to D. X. Niu; niudx617@gmail.com

Received 10 June 2014; Accepted 23 August 2014

Academic Editor: Carsten Proppe

Copyright (C) 2015 L. Ji et al. This is an open access article distributed under the Creative Commons Attribution License, which permits unrestricted use, distribution, and reproduction in any medium, provided the original work is properly cited.

The main goal of this paper is to provide a novel risk aversion model for long-term electric power system planning from the manager's perspective with the consideration of various uncertainties. In the proposed method, interval parameter programming and two-stage stochastic programming are integrated to deal with the technical, economics, and policy uncertainties. Moreover, downside risk theory is introduced to balance the trade-off between the profit and risk according to the decision-maker's risk aversion attitude. To verify the effectiveness and practical application of this approach, an inexact stochastic risk aversion model is developed for regional electric system planning and management in Ningxia Hui Autonomous Region, China. The series of solutions provide the decision-maker with the optimal investment strategy and operation management under different future emission reduction scenarios and risk-aversion levels. The results indicated that pollution control devices are still the main measures to achieve the current mitigation goal and the adjustment of generation structure would play an important role in the future cleaner electricity system with the stricter environmental policy. In addition, the model can be used for generating decision alternatives and helping decision-makers identify desired energy structure adjustment and pollutants/carbon mitigation abatement policies under various economic and system-reliability constraints.

\section{Introduction}

In recent years, with more concern on environmental aspects, achieving sustainable social development is an important challenge faced by many countries around the world. In particular, for China, haze weather, mainly caused by coal-fired power plants, heavy industry, and vehicles, is responsible for respiratory illness, stroke, heart disease, cancer, and birth defects. The amount of sulfur dioxide $\left(\mathrm{SO}_{2}\right)$ and nitrogen oxide $\left(\mathrm{NO}_{x}\right)$ emission from thermal power industry accounts for more than $40 \%$ of the national emissions in China. Electricity industry has been one of the main contributors to environment degradation with a larger amount of $\mathrm{SO}_{2}$, $\mathrm{NO}_{x}$, and particle pollution (PM) emission and ever-growing power demand [1]. Many researches have been done to seek the trade-off between energy system and environment system [2]. Although various emission control schemes have been pushing forward in order to meet even stricter air pollution standards, the actual environmental quality has not been improved duo to many challenges in the processes of environment-friendly energy systems management. Firstly, energy systems are complicated with uncertainties that may exist in many system parameters (e.g., power load demand, energy prices, and available resources) [3]; their 
interrelationships would intensify the competitive issue of energy system planning and environmental quality management. Secondly, regional decision-makers are facing difficulties in dealing with the inevitable conflicts between economic and environmental goals under the stricter pollution control policy [4]. Therefore, reasonable and effective regional electricity system planning constrained by environmental quality under uncertainty is desired.

Previously, a number of inexact optimization methods were developed for reflecting the uncertainties/complexities and managing energy and environmental planning under uncertainty, including included fuzzy mathematical programming (FMP), stochastic mathematical programming (SMP), chance-constrained programming (CCP), and interval parameter programming (IPP) [5-11]. For example, Guo et al. (2008) developed an interval chance-constraint semiinfinite programming for regional energy system planning under uncertainties, where energy sources allocation, fuel prices, environmental regulations, and regional energy structure were desired [12]. Xie et al. (2010) proposed an interval fixed-mix stochastic programming model for greenhouse gas emissions reduction management in a regional energy system under uncertainties [13]. Li and Huang (2012) proposed a scenario-based multistage interval-stochastic integer programming model for electric-power system planning with environmental emission management under uncertainty [14]. Dong et al. (2013) developed a fuzzy radial interval linear programming model for robust planning of energy management system, in which the uncertainties were expressed as fuzzy sets and regular and radial intervals [15]. Cai et al. (2009) developed a fuzzy-random interval programming model for energy management systems strategy optimization under multiple uncertainties [16]. Ji et al. (2014) proposed a two-stage stochastic inexact robust optimization model for residential microgrid energy management, where combined cooling, heating, and electricity technology were introduced to satisfy various energy demands [17]. Among these techniques, inexact two-stage stochastic programming (ITSP) with recourse, integrated interval-parameter programming, and two-stage stochastic programming (TSP) could deal with uncertainties expressed as probability distributions and discrete intervals and received extensive attentions over the past years [18-20]. In the ITSP model, an initial energyrelated decision is first undertaken before the random events happen; after the random information associated with the stochastic nature of emission-reduction targets is known, a second-stage decision can be made in order to minimize "penalties" that may appear due to any infeasibility. In general, ITSP is effective for problems where an analysis of policy scenarios is desired and was successfully applied in many fields. A remarkable limitation of the methods is their incapability in reflecting the risk of failing to limit a cost target (or reach an income target) and enhancing the system stability in regional energy system management with multiple power-generating technologies, due to considering the minimum cost or maximum net benefit as the system optimization objective [21].

Failure to consider the risk would lead to unrealistic expectations in investment profits and even investment losses. Since the construction of electricity facilities is irreversible and extremely expensive, it is imperative to deal with investment and operation risk cautiously [22]. In order to reflect such risk aversion in energy system management, downside risk was proposed to measure the system variability for a risk-averse energy system manager. The downside risk methods consider any cost above the fixed investment as a risk, measure risk below a certain point, and take all deviations below a target level into consideration [23, 24]. Downside risk has been applied in many risk management studies, like investment portfolio, water quality management, and energy market [25-27]. Nevertheless, few studies have been found in developing an inexact twostage stochastic downside risk-aversion (ITSDP) model for supporting regional electric-power systems planning under a general regional pollutants emission mitigation and electricity demand management framework.

Therefore, considering the recent liberalization of the electricity markets and the long-term electricity system planning with maximum profits and risk-aversion from the manager's perspective, the objective of this study is to developed an inexact two-stage stochastic downside riskaversion model for electricity system planning and environmental pollution reduction management over a longterm planning horizon in Ningxia Hui Autonomous Region (Ningxia), China. This objective entails the following: (i) combination of interval parameter programming, two-stage stochastic programming, and downside risk method into a general planning framework for reflecting the uncertainties/complexities in regional energy-environmental systems; (ii) development of a regional energy-environmental systems management model to address interactions among energy supply, power generation, and load demand and air pollutants emissions; (iii) application of the developed method for regional electric-power systems planning with different emission mitigation level and risk-aversion attitudes in Ningxia Hui Autonomous Region (Ningxia), China. The proposed model will help obtain multiple power generation schemes under different environmental requirements, income targets and risk levels, which are valuable for creating an ecofriendly society and maintaining the sustainable development of regional energy system.

\section{Methodology}

Two-stage stochastic programming (TSP) could provide feasible solutions for programming problems under uncertainties. In TSP, the uncertain parameters are usually expressed as probability distribution functions (PDFs) [28, 29]. In TSP, decision variables are divided into two subsets: those that must be determined before the realizations of random variables are known and those (recourse variables) that are determined after the realized values of the random variables are available. A general TSP model can be formulated as follows [30]:

$$
\max f=c^{T} x-\sum_{s=1}^{N} p_{s} Q\left(y, \omega_{s}\right)
$$


subject to

$$
\begin{gathered}
a x \leq b \\
T\left(\omega_{s}\right) x+W\left(\omega_{s}\right) y=h\left(\omega_{s}\right) \\
x \geq 0, \quad y\left(\omega_{s}\right) \geq 0,
\end{gathered}
$$

where $x$ is vector of first-stage decision variables; $c^{T} x$ is first-stage benefits; $\omega$ is random events after the first-stage decisions are made; $s$ is the scenario of the happening of random events; $p_{s}$ is probability of event $\omega_{s} ; T\left(\omega_{s}\right), W\left(\omega_{s}\right), h\left(\omega_{s}\right)$ are model parameters with reasonable dimensions (random parameters); $Q\left(y, \omega_{s}\right)$ is system recourse at the second stage under the occurrence of event $\omega_{s} ; \sum_{s=1}^{N} p_{s} Q\left(y, \omega_{s}\right)$ is expected value of the second-stage system penalties.

Although the TSP models could deal with probabilistic uncertainties in the model's right-hand sides which are often related to resources availability, they have difficulties in handling independent uncertainties of the model's left-hand sides and cost coefficients. Interval-parameter programming is an alternative for handling uncertainties in the model's left- and/or right-hand sides as well as those that cannot be quantified as membership or distribution functions, since interval numbers are acceptable as its uncertain inputs [31]. Assume $x^{ \pm}$to be a set of intervals with crisp lower bound (e.g., $x^{-}$) and upper bounds (i.e., $x^{+}$), without information about distribution. Thus, a set of closed and bounded interval numbers $x$ could be denoted as $x^{ \pm}[32]$ :

$$
x^{ \pm}=\left[x^{-}, x^{+}\right]=\left\{t \mid x^{-} \leq t \leq x^{+}\right\} \text {. }
$$

Introducing interval parameters into conventional ITSP model, the models (1a)-(1d) could be further modified as follows [33]:

$$
\max f^{ \pm}=c^{ \pm} x^{ \pm}-\sum_{s=1}^{N} p_{s} Q\left(y^{ \pm}, \omega_{s}^{ \pm}\right)
$$

subject to

$$
\begin{gathered}
a^{ \pm} x^{ \pm} \leq b^{ \pm}, \\
T\left(\omega_{s}^{ \pm}\right) x^{ \pm}+W\left(\omega_{s}^{ \pm}\right) y^{ \pm}=h\left(\omega_{s}^{ \pm}\right), \\
x^{ \pm} \geq 0, \quad y\left(\omega_{s}^{ \pm}\right) \geq 0 .
\end{gathered}
$$

On the other hand, the goal of the ITSP model could be maximizing the total expected profit (or minimizing the total expected cost). While considering risk management, it fails to provide appropriate strategies to achieving minimum profits (or controlling maximum costs) over the different scenarios. Thus, risk management theory should be added to increase the feasibility and reliability of the programming system.

According to previous research on risk management, downside risk theory is a successful approach to assess and manage risk. It can assist to incorporate risk concern (i.e., the tradeoff between the expected value and variability of the expected value) into optimization models. To present the concept of downside risk, we define $\delta(x, \Omega)$ as the positive deviation from a profit target $\Omega$ for design $x$ and $\operatorname{Profit}(x)$ as the benefit during the planning horizon; that is,

$$
\delta(x, \Omega)= \begin{cases}\Omega-\operatorname{Profit}(x), & \text { if Profit }(x)<\Omega \\ 0 & \text { if Profit }(x) \geq \Omega\end{cases}
$$

Downside risk is then defined as the expected value of $\delta(x, \Omega)$

$$
\operatorname{DRisk} \delta(x, \Omega)=E[\delta(x, \Omega)] \text {. }
$$

To incorporate the concept of downside risk in the framework of two-stage stochastic models, let $\delta_{s}(x, \Omega)$ present the positive deviation from the profit target $\Omega$ for design $x$ and scenario $s$ defined as follows [34]:

$$
\delta_{s}(x, \Omega)= \begin{cases}\Omega-\text { Profit }_{s}(x), & \text { if } \operatorname{Profit}_{s}(x)<\Omega \\ 0 & \text { if } \operatorname{Profit}_{s}(x) \geq \Omega\end{cases}
$$

$\forall s$.

Because the scenarios are probabilistically independent, the expected value of $\delta_{s}(x, \Omega)$ (i.e., downside risk) can be expressed as the following linear function of $\delta$ :

$$
\operatorname{DRisk} \delta(x, \Omega)=\sum_{s=1}^{N} p_{s} \delta_{s}(x, \Omega) .
$$

Based on the definitions of downside risk, it is found that downside risk is an expectation in income/cost, which is quite different from the definition of other risk measures that represents a probability value. Moreover, $\operatorname{DRisk} \delta(x, \Omega)$ is a continuous linear measure because it does not require the use of binary variables in the two-stage stochastic formulation [35]. This is a highly desirable property to potentially reduce the computational requirements of the models to manage risk. If the decision-maker is risk averse, he/she would prefer the lower risk. In this case, we can introduce a downside risk into the ITSP model to averse the risk. The schematic diagram of the proposed inexact two-stage stochastic downside risk-aversion programming is illustrated in Figure 1. Therefore, an inexact two-stage stochastic downside riskaversion programming can be formulated as follows:

$$
\max f^{ \pm}=c^{ \pm} x^{ \pm}-\sum_{s=1}^{N} p_{s} Q\left(y^{ \pm}, \omega_{s}^{ \pm}\right)
$$




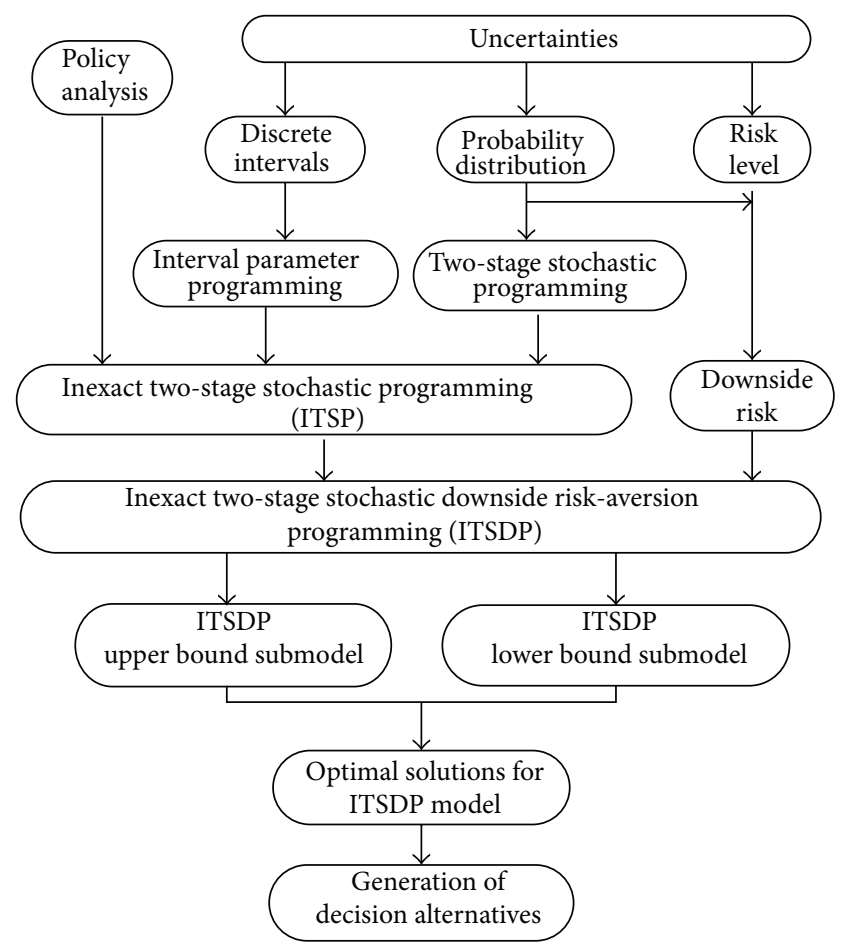

FIGURE 1: Schematic diagram of inexact two-stage stochastic downside risk-aversion programming.

subject to

$$
\begin{aligned}
& a^{ \pm} x^{ \pm} \leq b^{ \pm}, \\
& T\left(\omega_{s}^{ \pm}\right) x^{ \pm}+W\left(\omega_{s}^{ \pm}\right) y^{ \pm}=h\left(\omega_{s}^{ \pm}\right), \\
& \operatorname{DRisk} \delta\left(x^{ \pm}, \Omega^{ \pm}\right)=\sum_{s=1}^{N} p_{s} \delta_{s}\left(x^{ \pm}, \Omega^{ \pm}\right) \leq \lambda \cdot \psi^{ \pm}, \\
& \operatorname{Profit}_{s}\left(x^{ \pm}\right)=c^{ \pm} x^{ \pm}-Q\left(y^{ \pm}, \omega_{s}^{ \pm}\right), \quad \forall s, \\
& \delta_{s}\left(x^{ \pm}, \Omega^{ \pm}\right) \\
& = \begin{cases}\Omega^{ \pm}-\operatorname{Profit}_{s}\left(x^{ \pm}\right), & \text {if } \operatorname{Profit}_{s}\left(x^{ \pm}\right)<\Omega^{ \pm} \\
0 & \text { if } \operatorname{Profit}_{s}\left(x^{ \pm}\right) \geq \Omega^{ \pm},\end{cases} \\
& x^{ \pm} \geq 0, \quad y\left(\omega_{s}^{ \pm}\right) \geq 0,
\end{aligned}
$$

where $\psi^{ \pm}$is the expected downside risk value that calculates through the solution of the ITSP model and $\lambda$ is a control factor to acquire a more stringent limitation of risk, $\lambda \in[0,1]$. By computing the objective function for different values of $\lambda$, we can obtain a series of solutions with the consideration of manager's risk tolerance.

Models (8a)-(8g) can be transformed into two deterministic submodels that correspond to the lower and upper bounds of desired objective function value. This transformation process is based on an interactive algorithm, which is different from the best/worst case analysis [33]. The objective function value corresponding to $f^{+}$is desired first because the objective is to maximize net system costs. The submodel to find $f^{+}$can be firstly formulated as follows (assume $B^{ \pm} \geq 0$ and $f^{ \pm} \geq 0$ ):

$$
\begin{aligned}
\operatorname{Max} f^{+}= & \sum_{j=1}^{k_{1}} c_{j}^{+} x_{j}^{+}+\sum_{j=k_{1}+1}^{n_{1}} c_{j}^{-} x_{j}^{-} \\
& -\sum_{l=1}^{k_{2}} \sum_{s=1}^{n} p_{s} d_{l}^{-} y_{l s}^{-}-\sum_{l=k_{2}+1}^{n_{2}} \sum_{s=1}^{n} p_{s} d_{l}^{+} y_{l s}^{+}
\end{aligned}
$$

subject to

$$
\begin{aligned}
& \sum_{j=1}^{k_{1}}\left|a_{r j}^{-}\right|^{-} \operatorname{sign}\left(a_{r j}^{-}\right) x_{j}^{+} \\
& +\sum_{j=k_{1}+1}^{n_{1}}\left|a_{r j}^{+}\right|^{+} \operatorname{sign}\left(a_{r j}^{+}\right) x_{j}^{-} \leq b_{r}^{+}, \quad \forall r, \\
& \sum_{j=1}^{k_{1}} T\left(\omega_{s}^{+}\right) x_{j}^{+}+\sum_{j=k_{1}+1}^{n 1} T\left(\omega_{s}^{+}\right) x_{j}^{-}+\sum_{l=1}^{k_{2}} W\left(\omega_{s}^{+}\right) y_{l s}^{-} \\
& +\sum_{l=k_{2}+1}^{n_{2}} W\left(\omega_{s}^{+}\right) y_{l s}^{+}=h\left(\omega_{s}^{+}\right), \quad \forall s, \\
& \operatorname{DRisk} \delta\left(x^{ \pm}, \Omega_{s}^{+}\right)=\sum_{s=1}^{N} p_{s} \delta_{s}\left(x^{ \pm}, \Omega^{+}\right) \leq \lambda \cdot \psi^{+}, \\
& \operatorname{Profit}_{s}\left(x^{ \pm}\right)=\sum_{j=1}^{k_{1}} c_{j}^{+} x_{j}^{+}+\sum_{j=k_{1}+1}^{n_{1}} c_{j}^{-} x_{j}^{-} \\
& -\sum_{l=1}^{k_{2}} d_{l}^{-} y_{l s}^{-}-\sum_{l=k_{2}+1}^{n_{2}} d_{l}^{+} y_{l s}^{+} \\
& \delta_{s}\left(x^{ \pm}, \Omega^{+}\right) \\
& = \begin{cases}\Omega^{+}-\operatorname{Profit}_{s}\left(x^{ \pm}\right), & \text {if } \operatorname{Profit}_{s}\left(x^{ \pm}\right)<\Omega^{+} \\
0 & \text { if } \operatorname{Profit}_{s}\left(x^{ \pm}\right) \geq \Omega^{+},\end{cases} \\
& \sum_{s=1}^{n} p_{s}=1 \\
& x_{j}^{-} \geq 0, \quad j=1,2, \ldots, k_{1}, \\
& x_{j}^{+} \geq 0, \quad j=k_{1}+1, k_{1}+2, \ldots, n_{1}, \\
& y_{l s}^{-} \geq 0, \quad \forall s ; l=1,2, \ldots, k_{2}, \\
& y_{l s}^{+} \geq 0, \quad \forall s ; l=k_{2}+1, k_{2}+2, \ldots, n_{2},
\end{aligned}
$$

where $x_{j}^{ \pm}, j=1,2, \ldots, k_{1}$, are interval variables with positive coefficients in the objective function; $x_{j}^{ \pm}, j=$ $k_{1}+1, k_{1}+2, \ldots, n_{1}$, are interval variables with negative 
coefficients; $y_{l s}^{ \pm}, l=1,2, \ldots, k_{2}$ and $s=1,2, \ldots, n$, are random variables with positive coefficients in the objective function; $y_{l s}^{ \pm}, l=k_{2}+1, k_{2}+2, \ldots, n_{2}$ and $s=1,2, \ldots, n$, are random variables with negative coefficients. Solutions of $x_{\text {jopt }}^{+}\left(j=1,2, \ldots, k_{1}\right), x_{\text {jopt }}^{-}\left(j=k_{1}+1, k_{1}+2, \ldots, n_{1}\right), y_{l s o p t}^{-}$ $\left(l=1,2, \ldots, k_{2}\right)$, and $y_{l s o p t}^{+}\left(l=k_{2}+1, k_{2}+2, \ldots, n_{2}\right)$ can be obtained through submodels $(9 \mathrm{a})-(9 \mathrm{k})$. Based on the above solutions, the second submodel for $f^{-}$can be formulated as follows:

$$
\begin{aligned}
\operatorname{Max} f^{-}= & \sum_{j=1}^{k_{1}} c_{j}^{-} x_{j}^{-}+\sum_{j=k_{1}+1}^{n_{1}} c_{j}^{+} x_{j}^{+} \\
& -\sum_{l=1}^{k_{2}} \sum_{s=1}^{n} p_{s} d_{1}^{+} y_{l s}^{+}-\sum_{l=k_{2}+1}^{n_{2}} \sum_{s=1}^{n} p_{s} d_{1}^{-} y_{l s}^{-}
\end{aligned}
$$

subject to

$$
\begin{aligned}
& \sum_{j=1}^{k_{1}}\left|a_{r j}^{+}\right|^{+} \operatorname{sign}\left(a_{r j}^{+}\right) x_{j}^{-} \\
& +\sum_{j=k_{1}+1}^{n_{1}}\left|a_{r j}^{-}\right|^{-} \operatorname{sign}\left(a_{r j}^{-}\right) x_{j}^{-} \leq b_{r}^{-}, \quad \forall r, \\
& \sum_{j=1}^{k_{1}} T\left(\omega_{s}^{-}\right) x_{j}^{-}+\sum_{j=k_{1}+1}^{n_{1}} T\left(\omega_{s}^{-}\right) x_{j}^{+}+\sum_{l=1}^{k_{2}} W\left(\omega_{s}^{-}\right) y_{l s}^{+} \\
& +\sum_{l=k_{2}+1}^{n_{2}} W\left(\omega_{s}^{-}\right) y_{l s}^{-}=h\left(\omega_{s}^{-}\right), \quad \forall s \\
& \operatorname{DRisk} \delta\left(x^{ \pm}, \Omega^{-}\right)=\sum_{s=1}^{N} p_{s} \delta_{s}\left(x^{ \pm}, \Omega^{-}\right) \leq \lambda \cdot \psi^{-} \text {, } \\
& \operatorname{Profit}_{s}\left(x^{ \pm}\right)=\sum_{j=1}^{k_{1}} c_{j}^{-} x_{j}^{-}+\sum_{j=k_{1}+1}^{n_{1}} c_{j}^{+} x_{j}^{+} \\
& -\sum_{l=1}^{k_{2}} d_{1}^{+} y_{l s}^{+}-\sum_{l=k_{2}+1}^{n_{2}} d_{1}^{-} y_{l s}^{-} \\
& \delta_{s}\left(x^{ \pm}, \Omega^{-}\right) \\
& = \begin{cases}\Omega^{-}-\text {Profit }_{s}\left(x^{ \pm}\right), & \text {if } \operatorname{Profit}_{s}\left(x^{ \pm}\right)<\Omega^{-} \\
0 & \text { if } \operatorname{Profit}_{s}\left(x^{ \pm}\right) \geq \Omega^{-},\end{cases} \\
& \forall s, \\
& \sum_{s=1}^{n} p_{s}=1 \\
& x_{\text {jopt }}^{+} \geq x_{j}^{-} \geq 0, \quad j=1,2, \ldots, k_{1}, \\
& 0 \leq x_{\text {jopt }}^{-} \leq x_{j}^{+}, \quad j=k_{1}+1, k_{1}+2, \ldots, n_{1}, \\
& y_{l s}^{+} \geq y_{l s o p t}^{-} \geq 0, \quad \forall s ; l=1,2, \ldots, k_{2}, \\
& y_{l s o p t}^{+} \geq y_{l s}^{-} \geq 0, \quad \forall s ; l=k_{2}+1, k_{2}+2, \ldots, n_{2} \text {. }
\end{aligned}
$$

Solutions of $x_{\text {jopt }}^{-}\left(j=1,2, \ldots, k_{1}\right), x_{\text {jopt }}^{+}\left(j=k_{1}+1, k_{1}+\right.$ $\left.2, \ldots, n_{1}\right), y_{l s o p t}^{+}\left(j=1,2, \ldots, k_{2}\right)$, and $y_{l s o p t}^{-}\left(j=k_{2}+1, k_{2}+\right.$ $\left.2, \ldots, n_{2}\right)$ can be obtained through submodels (10a)-(10k). Through integrating solutions of submodels (9a)-(9k) and (10a)-(10k), interval solution for models $(8 \mathrm{a})-(8 \mathrm{~g})$ can be obtained

$$
\begin{aligned}
f_{\mathrm{opt}}^{ \pm} & =\left[x_{\text {jopt }}^{-}, x_{\text {jopt }}^{+}\right], \\
x_{\text {jopt }}^{ \pm} & =\left[x_{\text {jopt }}^{-}, x_{\text {jopt }}^{+}\right], \\
y_{l s \mathrm{opt}}^{ \pm} & =\left[y_{l s \mathrm{opt}}^{-}, y_{l s \mathrm{opt}}^{+}\right] .
\end{aligned}
$$

\section{Case Study}

3.1. The Electricity Sector in Ningxia. Ningxia Hui Autonomous Region (simply "Ningxia" for short), located in northwestern China $\left(35^{\circ} 17^{\prime} \sim 39^{\circ} 23^{\prime} \mathrm{N}, 104^{\circ} 17^{\prime} \sim 107^{\circ} 39^{\prime} \mathrm{E}\right)$, covers an area of $10684.9 \mathrm{~km}^{2}$ and governs five prefecture-level cities, named Yinchuan, Zhongwei, Guyuan, Wuzhong, and Shizuishan (Figure 2). From the Ningxia statistical yearbook of 2013, Ningxia has a population of 6.47 million, with gross domestic product of 232.664 billion Yuan in 2012, and Ningxia is an important base of energy industry and petrochemical industry. The prognostic coal reserves is $202.7 \times$ $10^{9}$ tones, and the explored coal reserves is $31.65 \times 10^{9}$ tones in Ningxia, where the total amount accounts for sixth place and the average amount per capita rank the first in China. In addition, due to the abundant coal resources in the region, the primary energy production was 62.36 million tones standard coal, where coal, crude oil, and renewable energy (hydropower, wind power, and photovoltaic power) accounted for $98.5 \%, 0.2 \%$, and $1.3 \%$ of the total amount in 2012, and the total energy consumption was 45.70 million tones standard coal, and the coal consumption accounted for $86.40 \%$ of the total energy consumption amount. Moreover, Ningxia is abundant in renewable and sustainable energy resources, especially solar energy and wind energy. The region locates in the northwest of China at high elevations with long sunshine hours (annual cumulative sunshine hours for 2250 3100 hours) and high solar radiation intensity (4950 6100 MJ/M on average). According to statistics of meteorological department, the total wind energy reserves in Ningxia are approximately $22.53 \mathrm{GWh}$, nearly half of which are available for wind power generation (12.14 GWh).

From the view of electric-power structure, the main power generation technologies include coal-fired power, gasfired power, and hydroelectric, wind, and solar power. By the end of year 2012, the total installed capacity in Ningxia reached $20 \mathrm{GW}$, where $16.40 \mathrm{GW}(81.99 \%)$ corresponded to thermal power plants, $0.43 \mathrm{GW}(2.13 \%)$ corresponded to hydropower plants, and $2.65 \mathrm{GW}(13.23 \%)$ and $0.53 \mathrm{GW}$ $(2.65 \%)$ corresponded to wind and solar power plants. In general, the power generation is to meet the regional socialeconomic development and sell surplus electricity to the other regions. In 2012, the power generation was $101.105 \times$ $10^{3} \mathrm{GWh}$, and the electricity consumption was $74.179 \times$ $10^{3} \mathrm{GWh}$, where the power generation by coal-fired power 


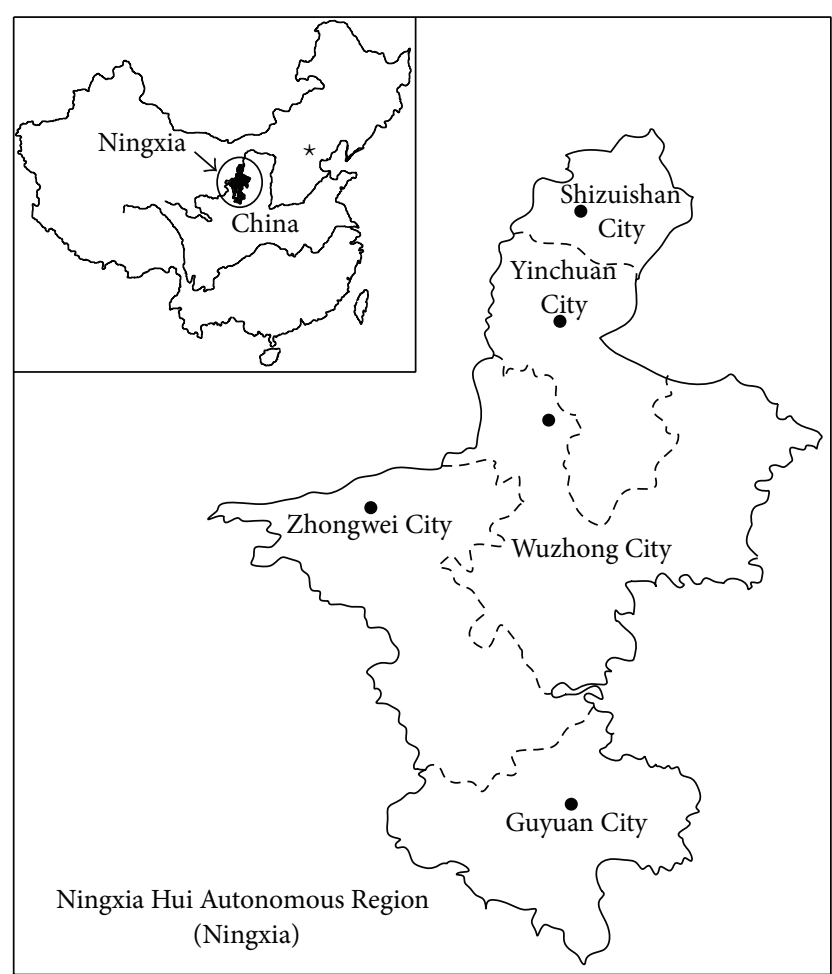

Figure 2: Map of Ningxia Hui Autonomous Region.

was $95.470 \times 10^{3} \mathrm{GWh}$ in Ningxia. Moreover, the local load demand increases steadily over the next two decades and the industrial electricity consumption accounts for 80 percentage of the total load demand. With the future economic development, a solution must be found to fill this energy gap and meet the long-term capacity needs. Besides, as an important energy base with abundance renewable energy, its clean electricity export also increases in recent years. Expansion plans should aim to adequately achieve electricity demand forecasts while meeting several additional criteria.

From the above analysis, electric industry of Ningxia, mainly based on coal-fired power, is one of the important industries in energy consumption. The power structure would lead to a serious environmental problem and a larger amount of pollutants emission. For example, in 2012, the total amount of sulfur dioxide $\left(\mathrm{SO}_{2}\right)$ emission was 406.60 kilotonnes, where the discharge amount form electric-power industry was 24.36 kilotonnes and accounted $52 \%$ of the total emission amount. As regional economic development and people's living standard improved, the power demand would be increase accordingly and enhance the robustness of the regional power grid and the stress of carbon and air pollutants mitigation. In order to change the electric-power structure, from the long-term and middle-term development plans of renewable energy, by the end of 2015, a large scale of renewable energy projects will be installed and the generation capacity of wind and solar power would be $5.00 \mathrm{GW}$ and $1.00 \mathrm{GW}$. Therefore, how to balance the contradiction between electricity demands and air pollution reduction goals and how to plan the development scale of renewable power conversion technologies in order to meet the optimization demand of electric-power structure and the goals of clean power generation would be the main challenge during the future regional power system development.

3.2. Mathematical Model Description. Consider that the future electricity demand during the planning horizon is often modeled as an uncertain parameter associated with a probability distribution, in order to achieve the regional electric-power system sustainable development. This study is to formulate an optimization model for determining the optimal investment timing and operational decisions that maximize the expected profit and minimize the associated risk over a time horizon of 15 years (2013-2027). The future profits are the electricity selling income after deducting the energy cost, generation operation cost, expansion cost, and emission treatment cost. Thus, the risk-constrained profitmaximization decision-making problem faced by regional electricity manager within the market framework can be formulated as follows:

$$
\operatorname{Max} f^{ \pm}=f_{1}^{ \pm}-f_{2}^{ \pm}-f_{3}^{ \pm}-f_{4}^{ \pm}-f_{5}^{ \pm},
$$

where $f^{ \pm}$is the expected profit for investment and management of electricity system over the planning horizon $\left(10^{9} \$\right)$.

Income:

$$
f_{1}^{ \pm}=\sum_{t}^{T} \sum_{h}^{H} p_{t h}\left(P L O C_{t}^{ \pm} D L O C_{t h}^{ \pm}+P E X_{t}^{ \pm} D E X_{t h}^{ \pm}\right),
$$

where $t$ is time period; $h$ means the electricity demand level ( $h=1,2$, and 3 for low, medium, and high level, resp.); $D L O C_{t h}^{ \pm}$and $D E X_{t h}^{ \pm}$represent the local load demand and export electricity during period $t$ (TWh); $P L O C_{t}^{ \pm}$and $P E X_{t}^{ \pm}$denote the local electricity price and regional trading electricity price $\left(\$ 10^{6} / \mathrm{TWh}\right)$.

Energy resources cost:

$$
f_{2}^{ \pm}=\sum_{i=1}^{I} \sum_{t=1}^{T} \sum_{h=1}^{H} p_{t h} P E_{i t}^{ \pm} R E_{i t}^{ \pm}\left(W_{i t}^{ \pm}+Q_{i t h}^{ \pm}\right),
$$

where $i$ is the type of power conversion technology, $i=1$ for coal-fired power, $i=2$ for natural gas-fired power, $i=3$ for hydropower, $i=4$ for wind power, and $i=5$ for solar power; $R E_{i}$ is the amount of energy consumption for per unit electricity through conversion technology $i$ (tonne/GWh).

Generation cost:

$$
f_{3}^{ \pm}=\sum_{i=1}^{I} \sum_{t=1}^{T} P V_{i t}^{ \pm} W_{i t}^{ \pm}+\sum_{i=1}^{I} \sum_{t=1}^{T} \sum_{h=1}^{H} p_{t h}\left(P V_{i t}^{ \pm}+P P_{i t}^{ \pm}\right) Q_{i t h}^{ \pm}
$$

where $P V_{i t}^{ \pm}$represent the operating cost of power conversion technology $i$ for preregulated electricity generation in period $t\left(\$ 10^{3} / \mathrm{GWh}\right) ; P P_{i t}^{ \pm}$represent the penalty cost of power conversion technology $i$ for excess electricity generation in period $t\left(\$ 10^{3} / \mathrm{GWh}\right) ; W_{i t}^{ \pm}$is the preregulated electricity generation target of power conversion technology $i$ which 
is promised to end users during period $t\left(10^{3} \mathrm{GWh}\right)$; $Q_{i t h}^{ \pm}$is the excess electricity generation of power conversion technology $i$ by which electricity generation target is exceeded when electricity demand level is $h$ in period $t\left(10^{3} \mathrm{GWh}\right)$.

Expansion cost:

$$
f_{4}^{ \pm}=\sum_{i=1}^{I} \sum_{t=1}^{T} \sum_{h=1}^{H} p_{t h}\left(A_{i t}^{ \pm} Y_{i t h}^{ \pm}+B_{i t}^{ \pm} X_{i t h}^{ \pm}\right)
$$

where $Y_{i t h}^{ \pm}$is binary variable for identifying whether or not a capacity expansion action of power conversion technology $i$ needs to be undertaken when electricity demand level is $h$ in period $t ; X_{i t h}^{ \pm}$is continuous variable about the amount of capacity expansion of power conversion technology $i$ when electricity demand level is $h$ in period $t(\mathrm{GW}) ; A_{i t}^{ \pm}$is the fixed-charge cost for capacity expansion of power conversion technology $i$ in period $t\left(\$ 10^{6}\right) ; B_{i t}^{ \pm}$is the variable cost for capacity expansion of power conversion technology $i$ in period $t\left(\$ 10^{6} / \mathrm{GW}\right)$.

Emission treatment cost:

$$
\begin{aligned}
f_{5}^{ \pm}= & \sum_{i=1}^{I} \sum_{j=1}^{J} \sum_{k=1}^{K_{j}} \sum_{t=1}^{T} C P_{j k t}^{ \pm} X P_{i j k t}^{ \pm} \\
& +\sum_{i=1}^{I} \sum_{j=1}^{J} \sum_{k=1}^{K_{j}} \sum_{t=1}^{T} \sum_{h=1}^{H} p_{t h} D P_{j k t}^{ \pm} Y P_{i j k t h}^{ \pm}
\end{aligned}
$$

where $j$ is the type of pollutant, $j=1,2$, and 3 for $\mathrm{SO}_{2}$, $\mathrm{NO}_{x}$, and particulate matter (PM), respectively; $k$ is the type of control measure. When $j=1, k=1$ for soda ash scrubber (SAS), $k=2$ for wet limestone scrubber (WLS), and $k=3$ for lime spray dryer (LSD); when $j=2, k=1$ for selective catalytic reduction (SCR), $k=2$ for selective noncatalytic reduction (SNCR); when $j=3, k=1$ for fabric filiter/baghouse $(\mathrm{BH}), k=2$ for electrostatic precipitator (ESP), and $k=3$ for wet collector (WC); $X P_{i j k t}^{ \pm}$represents preregulated amount of pollutant $j$ generated from power conversion technology $i$ to be mitigated by control measure $k$ in period $t$ (tonne); $Y P_{i j k t h}^{ \pm}$represents excess amount of pollution $j$ generated from power conversion technology $i$ to be mitigated by control measure $k$ when electricity demand level is $h$ in period $t$ (tonne). $C P_{j k t}^{ \pm}$is the operation cost of control measure $k$ for preregulated pollutant $j$ emissions during period $t$ (\$/tonne); $D P_{j k t}^{ \pm}$is the operation and penalty cost of control measure $k$ for excess pollutant $j$ emissions during period $t$ ( $\$ /$ tonne); $p_{t h}$ is the probability of demand level $h$ occurrence in period $t$, subject to the following.

(1) Energy Resources Constraints. In energy resources supply and conversion processes, it should ensure that energy demands for end users (industry, municipality, and transportation) and conversion activities are less than the supplies through local production and imports,

$$
\left(W_{i t}^{ \pm}+Q_{i t h}^{ \pm}\right) R E_{i t}^{ \pm} \leq U P R_{i t}^{ \pm}, \quad \forall i, t, h,
$$

where $U P R_{i t}^{ \pm}$is the upper bound of the resource availability for conversion technology $i$ in period $t\left(10^{3} \mathrm{TJ}\right)$.

(2) Electricity Balance Constraints. According to the principle of supply security and saving and effective use of power resources, the total amount of power generation should not be less than the load demand of different departments in the system,

$$
\sum_{i=1}^{I}\left(W_{i t}^{ \pm}+Q_{i t h}^{ \pm}\right) \geq D_{l o c t h}^{ \pm}+D_{e x t h}^{ \pm}, \quad \forall t, h,
$$

where $D_{\text {locth }}^{ \pm}$and $D_{\text {exth }}^{ \pm}$represent the local and exported electricity demand in period $t$ under $h$ level (TWh).

(3) Generation Technology Constraints. In the process of power supply, the electricity generation capacities of different conversation technologies determine the amount of power supply in each regional. The electricity generation should not be greater than the maximum ability,

$$
W_{i t}^{ \pm}+Q_{i t h}^{ \pm} \leq S T_{i t}^{ \pm}\left\{R C_{i}+\sum_{t^{\prime}=1}^{t} X_{i t h}^{ \pm}\right\}, \quad \forall i, t, h,
$$

where $S T_{i t}$ is the average service time of power conversion technology $i$ in period $t(h)$; $R C_{i}$ is the residual capacity of conversion technology $i(\mathrm{GW})$.

(4) Expansion Constraints. For each power conversation technology, the amount of its production should be less than the total installed capacity. In addition, if this requirement is violated, additional capacities will be installed,

$Y_{i t h}^{ \pm} \begin{cases}=1, & \text { if capacity expansion is undertaken, } \\ =0, & \text { if otherwise, }\end{cases}$

$\forall i, t, h$,

$$
N_{i t} \leq X_{i t h}^{ \pm} \leq M_{i t} Y_{i t h}^{ \pm}, \quad \forall i, t, h
$$

(5) Pollutant and $\mathrm{CO}_{2}$ Emission Calculation. Consider

$$
\begin{gathered}
\sum_{k}^{K_{j}} X P_{i j k t}^{ \pm}=W_{i t}^{ \pm} I N P_{i j t}^{ \pm}, \quad \forall i, j, t, \\
\sum_{k}^{K_{j}} Y P_{i j k t h}^{ \pm}=Q_{i t h}^{ \pm} I N P_{i j t}^{ \pm}, \quad \forall i, j, t, h,
\end{gathered}
$$

where $I N P_{i j t}^{ \pm}$denotes the pollutant $j$ emission of per unit electricity production for power conversion technology $i$ in period $t$ (tonne/GWh).

(6) Emission Constraint. The air pollutants treatment facilities should be set up to protect the environment from pollution, and the discharge amount from the power generation process 
TABLE 1: Regional electricity demands and electricity generation targets.

\begin{tabular}{|c|c|c|c|c|c|c|}
\hline Time period & \multicolumn{2}{|c|}{$t=1$} & \multicolumn{2}{|c|}{$t=2$} & \multicolumn{2}{|c|}{$t=3$} \\
\hline \multicolumn{7}{|c|}{ Demand level probability (\%) } \\
\hline Low (L) & \multicolumn{2}{|c|}{25} & \multicolumn{2}{|c|}{20} & \multicolumn{2}{|c|}{15} \\
\hline Medium (M) & \multicolumn{2}{|c|}{50} & \multicolumn{2}{|c|}{60} & \multicolumn{2}{|c|}{55} \\
\hline $\operatorname{High}(\mathrm{H})$ & \multicolumn{2}{|c|}{25} & \multicolumn{2}{|c|}{20} & \multicolumn{2}{|c|}{30} \\
\hline \multicolumn{7}{|c|}{ Local total electricity demand $\left(10^{3} \mathrm{GWh}\right)$} \\
\hline Demand level & Local demand & Expert electricity & Local demand & Expert electricity & Local demand & Expert electricity \\
\hline Low (L) & {$[335,350]$} & {$[110,120]$} & {$[350,370]$} & {$[130,140]$} & {$[365,385]$} & {$[150,180]$} \\
\hline Medium (M) & {$[335,375]$} & {$[125,135]$} & {$[375,400]$} & {$[140,140]$} & {$[390,420]$} & {$[165,180]$} \\
\hline $\operatorname{High}(\mathrm{H})$ & {$[380,390]$} & {$[140,150]$} & {$[400,415]$} & {$[150,165]$} & {$[425,440]$} & {$[180,195]$} \\
\hline \multicolumn{7}{|c|}{ Electricity generation targets of each power conversion technology $\left(10^{3} \mathrm{GWh}\right)$} \\
\hline Coal-fired power, $W_{1 t}^{ \pm}$ & \multicolumn{2}{|c|}{$[157.5,280]$} & \multicolumn{2}{|c|}{$[155,260]$} & \multicolumn{2}{|c|}{$[152.5,250]$} \\
\hline Gas-fired power, $W_{2 t}^{ \pm}$ & \multicolumn{2}{|c|}{$[30,100]$} & \multicolumn{2}{|c|}{$[35,125]$} & \multicolumn{2}{|c|}{$[40,150]$} \\
\hline Hydropower, $W_{3 t}^{ \pm}$ & \multicolumn{2}{|c|}{$[25,50]$} & \multicolumn{2}{|c|}{$[27.5,75]$} & \multicolumn{2}{|c|}{$[30,120]$} \\
\hline Wind power, $W_{4 t}^{ \pm}$ & \multicolumn{2}{|c|}{$[10,40]$} & \multicolumn{2}{|c|}{$[10,45]$} & \multicolumn{2}{|c|}{$[10,55]$} \\
\hline Solar power, $W_{5 t}^{ \pm}$ & \multicolumn{2}{|c|}{$[5,25]$} & \multicolumn{2}{|c|}{$[5,35]$} & \multicolumn{2}{|c|}{$[5,45]$} \\
\hline
\end{tabular}

should not excess the maximum availability of pollutants emission,

$$
\sum_{i=1}^{I} \sum_{k=1}^{K_{j}}\left(1-\eta_{j k}^{ \pm}\right)\left(X P_{i j k t}^{ \pm}+Y P_{i j k t h}^{ \pm}\right) \leq E P_{j t}^{ \pm}, \quad \forall t, j, h, \quad(12 \mathrm{o})
$$

where $\eta_{j k}$ represents the average control measure efficiency for $j$ pollutant handled by $k$ measure. $E P_{j t}$ is the emission allowance of $j$ pollutant in period $t$.

(7) Downside Risk-Aversion Constraint. According to the regional development planning, the income from energy sector would have a profit target and it should control the risk of violating the income target within limits,

$$
\begin{aligned}
\text { Profit }(t, h)= & P_{l o c}^{ \pm} D_{l o c t h}^{ \pm}+P_{e x}^{ \pm} D_{e x t h}^{ \pm} \\
- & {\left[P E C_{t}^{ \pm} R E_{1 t h}\left(W_{1 t}^{ \pm}+Q_{1 t h}^{ \pm}\right)\right.} \\
& \left.+P E N_{t}^{ \pm} R E_{2 t h}^{ \pm}\left(W_{2 t}^{ \pm}+Q_{2 t h}^{ \pm}\right)\right] \\
& -\sum_{i=1}^{I} P V_{i t}^{ \pm} W_{i t}^{ \pm}-\sum_{i=1}^{I}\left(P V_{i t}^{ \pm}+P P_{i t}^{ \pm}\right) Q_{i t h}^{ \pm} \\
& -\sum_{i=1}^{I}\left(A_{i t}^{ \pm} Y_{i t h}^{ \pm}+B_{i t}^{ \pm} X_{i t h}^{ \pm}\right) \\
& -\sum_{i=1}^{I} \sum_{j=1}^{J} \sum_{k=1}^{K_{j}} C P_{j k t}^{ \pm} X P_{j k t}^{ \pm} \\
& -\sum_{i=1}^{I} \sum_{j=1}^{J} \sum_{k=1}^{K_{j}} D P_{j k t}^{ \pm} Y P_{i j k t h}^{ \pm}, \quad \forall t, h,
\end{aligned}
$$

$$
\begin{array}{r}
\delta_{t h}\left(\Omega_{t}^{ \pm}\right)= \begin{cases}\Omega_{t}^{ \pm}-\operatorname{Profit}(t, h), & \text { if Profit }(h, t)<\Omega_{t}^{ \pm} \\
0 & \text { if Profit }(h, t) \geq \Omega_{t}^{ \pm}, \\
\forall t, h,\end{cases} \\
\operatorname{DRisk\delta }\left(\Omega_{t}^{ \pm}\right)=\sum_{h=1}^{H} p_{h} \delta_{t h}\left(\Omega_{t}^{ \pm}\right) \leq \lambda \psi_{t}^{ \pm}, \quad \forall t,
\end{array}
$$

where $P E C_{t}^{ \pm}$and $P E N_{t}^{ \pm}$are the price of coal and natural gas in period $t\left(\$ 10^{3} / \mathrm{TJ}\right)$, respectively.

3.3. Data Collection. The planning horizon is divided into three periods with each one representing a 5-year span. New power plants are desired to satisfy the future local electricity demand and export demand. Under pollution reduction policy, renewable energy generation is encouraged to adjust the generation structure. The forecasted value of electricity demand and future generation targets is presented in Table 1. Considering the economic and social uncertainties, the future electricity demands are assumed to be at high, medium, and low level with the respective possibility. Economic and technological parameters of each power conversion technology are time dependent parameters, which are listed in Table 2 . Three main pollutions $\left(\mathrm{SO}_{2}, \mathrm{NO}_{x}\right.$, and $\mathrm{PM}$ ) are strictly controlled. There is a range of pollution control technologies available to retrofit current power plants. For instance, for $\mathrm{SO}_{2}$ treatment, there are soda ash scrubber (SAS), wet limestone scrubber (WLS), and lime spray dryer (LSD). Table 3 shows the regular and penalty costs of different pollution control techniques. Except the uncertainties of economic development, the external environmental policy is also a key factor influencing the decision. 
TABLE 2: Economic and technological parameters of different generation technologies.

\begin{tabular}{|c|c|c|c|}
\hline \multirow{2}{*}{ Conversion technology } & \multicolumn{3}{|c|}{ Time period } \\
\hline & $t=1$ & $t=2$ & $t=3$ \\
\hline & \multicolumn{3}{|c|}{ Regular and surplus costs for power generation by each power conversion technology $\left(\$ 10^{6} / 10^{3} \mathrm{GWh}\right)$} \\
\hline \multicolumn{4}{|l|}{ Coal-fired power } \\
\hline Regular cost, $P V_{1 t}^{ \pm}$ & {$[5.0,5.2]$} & {$[5.5,5.7]$} & {$[6.0,6.2]$} \\
\hline Surplus cost, $P P_{1 t}^{ \pm}$ & {$[3.0,3.3]$} & {$[3.5,4.0]$} & {$[4.0,4.2]$} \\
\hline \multicolumn{4}{|l|}{ Gas-fired power } \\
\hline Regular cost, $P V_{2 t}^{ \pm}$ & {$[4.5,6.5]$} & {$[5.0,7.0]$} & {$[5.5,7.5]$} \\
\hline Surplus cost, $P P_{2 t}^{ \pm}$ & {$[2.5,2.8]$} & {$[3.0,3.3]$} & {$[3.5,3.8]$} \\
\hline \multicolumn{4}{|l|}{ Hydropower } \\
\hline Regular cost, $P V_{3 t}^{ \pm}$ & {$[4.0,6.0]$} & {$[4.5,6.5]$} & {$[5.0,7.0]$} \\
\hline Surplus cost, $P P_{3 t}^{ \pm}$ & {$[1.8,2.2]$} & {$[2.0,2.6]$} & {$[2.5,3.4]$} \\
\hline \multicolumn{4}{|l|}{ Wind power } \\
\hline Regular cost, $P V_{4 t}^{ \pm}$ & {$[2.5,3.5]$} & {$[3.0,4.0]$} & {$[3.5,4.5]$} \\
\hline Surplus cost, $P P_{4 t}^{ \pm}$ & {$[1.5,1.8]$} & {$[2.0,2.3]$} & {$[2.5,2.8]$} \\
\hline \multicolumn{4}{|l|}{ Solar power } \\
\hline Regular cost, $P V_{5 t}^{ \pm}$ & {$[2.0,3.0]$} & {$[2.5,3.5]$} & {$[3.0,4.0]$} \\
\hline Surplus cost, $P P_{5 t}^{ \pm}$ & {$[1.0,1.3]$} & {$[1.5,1.8]$} & {$[2.0,2.2]$} \\
\hline \multicolumn{4}{|c|}{ Fixed $\left(\$ 10^{6}\right)$ and variable $\left(\$ 10^{6} / \mathrm{GW}\right)$ costs for capacity expansion } \\
\hline \multicolumn{4}{|l|}{ Coal-fired power } \\
\hline Fixed cost, $A_{1 t}^{ \pm}$ & {$[325,335]$} & {$[330,345]$} & {$[335,345]$} \\
\hline Variable cost, $B_{1 t}^{ \pm}$ & {$[700,715]$} & {$[710,725]$} & {$[720,735]$} \\
\hline \multicolumn{4}{|l|}{ Gas-fired power } \\
\hline Fixed cost, $A_{2 t}^{ \pm}$ & {$[300,315]$} & {$[310,325]$} & {$[320,330]$} \\
\hline Variable cost, $B_{2 t}^{ \pm}$ & {$[650,660]$} & {$[655,665]$} & {$[660,670]$} \\
\hline \multicolumn{4}{|l|}{ Hydropower } \\
\hline Fixed cost, $A_{3 t}^{ \pm}$ & {$[700,715]$} & {$[710,725]$} & {$[720,730]$} \\
\hline Variable cost, $B_{3 t}^{ \pm}$ & {$[1800,1820]$} & {$[1815,1830]$} & {$[1825,1835]$} \\
\hline \multicolumn{4}{|l|}{ Wind power } \\
\hline Fixed cost, $A_{4 t}^{ \pm}$ & {$[800,812]$} & {$[810,822]$} & {$[820,830]$} \\
\hline Variable cost, $B_{4 t}^{ \pm}$ & {$[1900,1915]$} & {$[1910,1925]$} & {$[1920,1935]$} \\
\hline \multicolumn{4}{|l|}{ Solar power } \\
\hline Fixed cost, $A_{5 t}^{ \pm}$ & {$[900,910]$} & {$[905,920]$} & {$[915,930]$} \\
\hline Variable cost, $B_{5 t}^{ \pm}$ & {$[2000,2025]$} & {$[2020,2035]$} & {$[2035,2045]$} \\
\hline
\end{tabular}

\section{Results Analysis}

In this study, three environmental policies with different pollutants mitigation levels will be considered (i.e., $0 \%, 20 \%$, and $30 \%$ reduction goal, resp.). Besides, different sets of $\lambda$ values (i.e., $\lambda=1.00,0.85,0.70)$ reflecting the decision-maker's risk attitude have been tested. For comparison purposes, planning without downside risk control is computed through the interval two-stage stochastic programming model. This model could be solved by LINGO software, and a series of optimal solutions can be obtained under different scenarios and $\lambda$ value. The above-formulated inexact two-stage stochastic programming model combined with downside risk was solved with Lingo on a computer Intel(R)-Core(TM) Duo with $3.00 \mathrm{GHz}$. The whole process took nearly 18 seconds, and a series of optimal solutions could be obtained under different scenarios and $\lambda$ value.

Table 4 provides the optimal power generation strategies for both predesigned and excess electricity generations under the scenario of $20 \%$ emission reduction goal and $\lambda=1.00$. The results indicated that optimized coal-fired power generation targets would be $280.00 \times 10^{3} \mathrm{GWh}, 260.00 \times 10^{3} \mathrm{GWh}$, and $250.00 \times 10^{3} \mathrm{GWh}$ in periods 1 to 3 , respectively, which are corresponding to their upper-bound targets. In comparison, the natural gas fired power and solar power generation targets would reach to their lower bound. For example, the optimized natural gas fired power would be $30.00 \times 10^{3} \mathrm{GWh}$, $35.00 \times 10^{3} \mathrm{GWh}$, and $41.64 \times 10^{3} \mathrm{GWh}$ in periods 1 to 3 , respectively; and the solar power generation targets would 
TABLE 3: Regular and penalty costs of pollution control techniques.

\begin{tabular}{|c|c|c|c|}
\hline \multirow{2}{*}{ Pollution control technique } & \multicolumn{3}{|c|}{ Time period } \\
\hline & $t=1$ & $t=2$ & $t=3$ \\
\hline \multicolumn{4}{|c|}{ Regular cost for treating preregulated $\mathrm{SO}_{2}$ emission ( $\$$ tonne) } \\
\hline SAS, $C P_{11 t}$ & {$[55,60]$} & {$[57,62]$} & {$[59,64]$} \\
\hline WLS, $C P_{12 t}$ & {$[45,50]$} & {$[48,53]$} & {$[51,55]$} \\
\hline LSD, $C P_{13 t}$ & {$[30,35]$} & {$[33,38]$} & {$[35,40]$} \\
\hline \multicolumn{4}{|c|}{ Penalty cost for treating excess $\mathrm{SO}_{2}$ emission ( $\$ /$ tonne) } \\
\hline SAS, $D P_{11 t}$ & {$[90,110]$} & {$[95,105]$} & {$[100,110]$} \\
\hline WLS, $D P_{12 t}$ & {$[125,135]$} & {$[130,140]$} & {$[135,145]$} \\
\hline LSD, $D P_{13 t}$ & {$[110,120]$} & {$[115,125]$} & {$[120,130]$} \\
\hline \multicolumn{4}{|c|}{ Regular cost for treating preregulated $\mathrm{NO}_{x}$ emission (\$/tonne) } \\
\hline $\mathrm{SCR}, \mathrm{CP}_{21 t}$ & {$[55,60]$} & {$[59,64]$} & {$[62,67]$} \\
\hline $\mathrm{SNCR}, C P_{22 t}$ & {$[35,40]$} & {$[38,43]$} & {$[40,45]$} \\
\hline \multicolumn{4}{|c|}{ Penalty cost for treating excess $\mathrm{NO}_{x}$ emission (\$/tonne) } \\
\hline $\mathrm{SCR}, D P_{21 t}$ & {$[95,105]$} & {$[100,110]$} & {$[105,115]$} \\
\hline SNCR, $D P_{22 t}$ & {$[110,120]$} & {$[115,125]$} & {$[120,130]$} \\
\hline \multicolumn{4}{|c|}{ Regular cost for treating preregulated PM emission (\$/tonne) } \\
\hline $\mathrm{BH}, \mathrm{CP}_{31 t}$ & {$[135,145]$} & {$[140,150]$} & {$[145,155]$} \\
\hline $\mathrm{ESP}, \mathrm{CP} P_{32 t}$ & {$[125,135]$} & {$[133,143]$} & {$[140,150]$} \\
\hline $\mathrm{WC}, \mathrm{CP}_{33 t}$ & {$[115,125]$} & {$[120,130]$} & {$[125,135]$} \\
\hline \multicolumn{4}{|c|}{ Penalty cost for treating excess PM emission (\$/tonne) } \\
\hline $\mathrm{BH}, D P_{31 t}$ & {$[185,195]$} & {$[193,203]$} & {$[200,210]$} \\
\hline ESP, $D P_{32 t}$ & {$[195,205]$} & {$[203,213]$} & {$[210,220]$} \\
\hline $\mathrm{WC}, D P_{33 t}$ & {$[205,215]$} & {$[213,223]$} & {$[220,230]$} \\
\hline
\end{tabular}

also be $5.00 \times 10^{3} \mathrm{GWh}$ during the whole planning period. The wind and hydropower generation targets would be close to their lower bound. This is mainly because the conversion technologies correspond to comparatively low, regular, and surplus operation costs, even though they have a high pollutant-emission rates, and the requirements of pollutant emission reduction have not affected the power generation structure. In addition, as the demand level increases, the excess power generation would be increased to fill the power shortage in the energy system and the coal-fired power and hydropower would be vitally important as the recourse action to compensate the deficits over the planning horizon. In general, the optimized electricity generated by coal-fired power technologies would account for over $70 \%$ of the total power generation. The renewable energy would play a greater role in the future, with governments offering incentive programs to make "green" energy a more economically viable option. For example, under the high demand level, the natural gas fired power, hydropower, and wind power generation would be increased from $30.00 \times 10^{3} \mathrm{GWh},[47.83,50.83] \times$ $10^{3} \mathrm{GWh}$, and $25.18 \times 10^{3} \mathrm{GWh}$ in period 1 to $[57.78,83.28] \times$ $10^{3} \mathrm{GWh},[57.26,61.76] \times 10^{3} \mathrm{GWh}$, and $28.49 \times 10^{3} \mathrm{GWh}$ in period 3 , respectively.

In order to satisfy the ambient air-quality requirement, an action plan for air pollution control would be implemented according to the national express provision for improving air quality. For the electric-power system in Ningxia, the treatment and emission amounts of pollutants during the planning horizon under the scenario of $20 \%$ emission reduction goal and $\lambda=1.00$ are presented in Table 5. The main atmospheric pollutant existing in the regional electric-power system would be $\mathrm{SO}_{2}$ and $\mathrm{NO}_{x}$ during the planning period. In detail, during period 1 , for the medium demand level, the optimal treatment amount of $\mathrm{SO}_{2}, \mathrm{NO}_{x}$, and $\mathrm{PM}$ would be $[4133.38,12314.59] \times 10^{6}$ tonne, $[1165.46,5384.11] \times 10^{6}$ tonne, and $[709.05,2065.13] \times 10^{6}$ tonne, respectively. The corresponding emission amount for this optimal strategy would be $[393.55,398.45] \times 10^{6}$ tonne, $551.76 \times 10^{6}$ tonne, and $[9.52,14.42] \times 10^{6}$ tonne, respectively. In addition, duo to the dominant proportion of coal electricity in its electricity energy formation, higher load demand would require more electricity supply, and thus more pollutants need to be treated accordingly. For example, during period 2, the treatment amount of $\mathrm{SO}_{2}$ would be $[1103.75,4123.25] \times 10^{6}$ tonne, $[1133.33,8676.78] \times 10^{6}$ tonne, and $[1103.75,17711.00] \times$ $10^{6}$ tonne under the low, medium, and high demand level, respectively. The $\mathrm{NO}_{x}$ treatment amount would be $[466.18,489.43] \times 10^{3}$ tonne, $[484.66,497.41] \times 10^{3}$ tonne, and $498.96 \times 10^{3}$ tonne under the three-demand level in period 3. Moreover, with the development of renewable energy sources, the amount of pollutants treatment and emission would have a slight decrease trend. For example, 
TABLE 4: Generation plan under $20 \%$ emission reduction goal with $\lambda=1.00$.

\begin{tabular}{|c|c|c|c|c|c|}
\hline \multirow{2}{*}{ Period } & \multirow{2}{*}{ Technology } & \multirow{2}{*}{ Level } & \multicolumn{3}{|c|}{ Power generation $\left(10^{3} \mathrm{GWh}\right)$} \\
\hline & & & $\begin{array}{c}\text { Optimized generation } \\
\text { target }\end{array}$ & $\begin{array}{c}\text { Optimized excess } \\
\text { generation }\end{array}$ & $\begin{array}{c}\text { Optimized generation } \\
\text { quantity }\end{array}$ \\
\hline \multirow{15}{*}{ Period 1} & \multirow{3}{*}{ Coal-fired power } & $\mathrm{L}$ & 280.00 & {$[64.50,89.50]$} & {$[344.50,369.50]$} \\
\hline & & M & 280.00 & {$[98.00,123.50]$} & {$[378.00,403.50]$} \\
\hline & & $\mathrm{H}$ & 280.00 & {$[132.00,149.00]$} & {$[412.00,429.00]$} \\
\hline & \multirow{3}{*}{ Natural gas fired power } & $\mathrm{L}$ & 30.00 & 0 & 30.00 \\
\hline & & M & 30.00 & 0 & 30.00 \\
\hline & & $\mathrm{H}$ & 30.00 & 0 & 30.00 \\
\hline & \multirow{3}{*}{ Hydropower } & $\mathrm{L}$ & 40.33 & 0 & 40.33 \\
\hline & & M & 40.33 & {$[1.50,6.00]$} & {$[41.83,46.33]$} \\
\hline & & $\mathrm{H}$ & 40.33 & {$[7.50,10.50]$} & {$[47.83,50.83]$} \\
\hline & \multirow{3}{*}{ Wind power } & $\mathrm{L}$ & 25.18 & 0 & 25.18 \\
\hline & & M & 25.18 & 0 & 25.18 \\
\hline & & $\mathrm{H}$ & 25.18 & 0 & 25.18 \\
\hline & \multirow{3}{*}{ Solar power } & $\mathrm{L}$ & 5.00 & 0 & 5.00 \\
\hline & & M & 5.00 & 0 & 5.00 \\
\hline & & $\mathrm{H}$ & 5.00 & 0 & 5.00 \\
\hline \multirow{15}{*}{ Period 2} & \multirow{3}{*}{ Coal-fired power } & $\mathrm{L}$ & 260.00 & {$[108.50,138.50]$} & {$[368.50,398.50]$} \\
\hline & & M & 260.00 & {$[142.75,164.00]$} & {$[402.75,424.00]$} \\
\hline & & $\mathrm{H}$ & 260.00 & {$[172.50,198.00]$} & {$[432.50,458.00]$} \\
\hline & \multirow{3}{*}{ Natural gas fired power } & $\mathrm{L}$ & 35.00 & 0 & 35.00 \\
\hline & & M & 35.00 & 0 & 35.00 \\
\hline & & $\mathrm{H}$ & 35.00 & 0 & 35.00 \\
\hline & \multirow{3}{*}{ Hydropower } & $\mathrm{L}$ & 43.68 & 0 & 43.68 \\
\hline & & M & 43.68 & {$[0.75,4.50]$} & {$[44.43,48.18]$} \\
\hline & & $\mathrm{H}$ & 43.68 & {$[6.00,10.50]$} & {$[49.68,54.18]$} \\
\hline & \multirow{3}{*}{ Wind power } & $\mathrm{L}$ & 27.23 & 0 & 27.23 \\
\hline & & M & 27.83 & 0 & 27.83 \\
\hline & & $\mathrm{H}$ & 27.83 & 0 & 27.83 \\
\hline & \multirow{3}{*}{ Solar power } & $\mathrm{L}$ & 5.00 & 0 & 5.00 \\
\hline & & M & 5.00 & 0 & 5.00 \\
\hline & & $\mathrm{H}$ & 5.00 & 0 & 5.00 \\
\hline \multirow{15}{*}{ Period 3} & \multirow{3}{*}{ Coal-fired power } & $\mathrm{L}$ & 250.00 & {$[141.61,171.61]$} & {$[391.61,421.61]$} \\
\hline & & M & 250.00 & {$[180.11,206.71]$} & {$[430.11,456.71]$} \\
\hline & & $\mathrm{H}$ & 250.00 & 206.47 & 456.47 \\
\hline & \multirow{3}{*}{ Natural gas fired power } & $\mathrm{L}$ & 41.64 & 0 & 41.64 \\
\hline & & M & 41.64 & {$[0,11.65]$} & {$[41.64,53.29]$} \\
\hline & & $\mathrm{H}$ & 41.64 & {$[16.14,41.64]$} & {$[57.78,83.28]$} \\
\hline & \multirow{3}{*}{ Hydropower } & $\mathrm{L}$ & 48.26 & 0 & 48.26 \\
\hline & & M & 48.26 & {$[1.50,8.25]$} & {$[49.76,56.51]$} \\
\hline & & $\mathrm{H}$ & 48.26 & {$[9.00,13.50]$} & {$[57.26,61.76]$} \\
\hline & \multirow{3}{*}{ Wind power } & $\mathrm{L}$ & 28.49 & 0 & 28.49 \\
\hline & & M & 28.49 & 0 & 28.49 \\
\hline & & $\mathrm{H}$ & 28.49 & 0 & 28.49 \\
\hline & \multirow{3}{*}{ Solar power } & $\mathrm{L}$ & 5.00 & 0 & 5.00 \\
\hline & & M & 5.00 & 0 & 5.00 \\
\hline & & $\mathrm{H}$ & 5.00 & 0 & 5.00 \\
\hline
\end{tabular}


TABLE 5: Pollutants treatment and emission amount under 20\% mitigation level with $\lambda=1.00$.

\begin{tabular}{|c|c|c|c|c|}
\hline \multirow{2}{*}{ Period } & \multirow{2}{*}{ Pollutant } & \multicolumn{3}{|c|}{ Demand level } \\
\hline & & Low & Medium & High \\
\hline \multicolumn{5}{|c|}{ Amount of pollutants treatment $\left(10^{6}\right.$ tonne $)$} \\
\hline \multirow{3}{*}{ Period 1} & $\mathrm{SO}_{2}$ & {$[2212.63,5036.96]$} & {$[4133.38,12314.59]$} & {$[4460.63,22938.89]$} \\
\hline & $\mathrm{NO}_{x}$ & {$[306.24,2022.24]$} & {$[1165.46,5384.11]$} & {$[335.64,9759.84]$} \\
\hline & PM & {$[264.87,803.20]$} & {$[709.05,2065.13]$} & {$[258.64,3216.14]$} \\
\hline \multirow{3}{*}{ Period 2} & $\mathrm{SO}_{2}$ & {$[1103.75,4123.25]$} & {$[1133.33,8676.78]$} & {$[1103.75,17711.00]$} \\
\hline & $\mathrm{NO}_{x}$ & {$[1341.98,2746.88]$} & {$[885.84,4821.60]$} & {$[1977.10,10716.46]$} \\
\hline & $\mathrm{PM}$ & {$[238.31,723.96]$} & {$[224.49,1439.56]$} & {$[742.92,3464.91]$} \\
\hline \multirow{3}{*}{ Period 3} & $\mathrm{SO}_{2}$ & {$[2366.67,5383.52]$} & {$[1017.87,8048.63]$} & {$[1017.87,16438.49]$} \\
\hline & $\mathrm{NO}_{x}$ & {$[388.80,1945.67]$} & {$[262.57,4075.25]$} & {$[261.03,8620.86]$} \\
\hline & $\mathrm{PM}$ & {$[590.97,1028.07]$} & {$[206.95,1352.50]$} & {$[216.20,2729.11]$} \\
\hline \multicolumn{5}{|c|}{ Amount of pollutants emission $\left(10^{3}\right.$ tonne $)$} \\
\hline \multirow{4}{*}{ Period 1} & $\mathrm{SO}_{2}$ & {$[402.69,421.40]$} & {$[393.55,398.45]$} & 421.40 \\
\hline & $\mathrm{NO}_{x}$ & 551.76 & 551.76 & {$[522.36,536.16]$} \\
\hline & $\mathrm{PM}$ & {$[2.00,3.53]$} & {$[9.52,14.42]$} & {$[4.66,9.76]$} \\
\hline & $\mathrm{SO}_{2}$ & 406.00 & {$[376.42,382.02]$} & 406.00 \\
\hline \multirow[t]{2}{*}{ Period 2} & $\mathrm{NO}_{x}$ & 525.36 & 525.36 & {$[486.62,493.57]$} \\
\hline & $\mathrm{PM}$ & {$[2.04,3.70]$} & {$[12.44,17.51]$} & {$[5.24,11.53]$} \\
\hline \multirow{3}{*}{ Period 3} & $\mathrm{SO}_{2}$ & 384.00 & {$[362.62,384.00]$} & 384.00 \\
\hline & $\mathrm{NO}_{x}$ & {$[466.18,489.43]$} & {$[484.66,497.41]$} & 498.96 \\
\hline & PM & {$[2.14,3.82]$} & {$[14.99,20.96]$} & {$[5.86,11.72]$} \\
\hline
\end{tabular}

under the high demand level, the amount of $\mathrm{SO}_{2}$ emission would be $421.40 \times 10^{3}$ tonne, $406.00 \times 10^{3}$ tonne, and $384.00 \times$ $10^{3}$ tonne in periods 1 to 3 , respectively. For a short term, coalfired power would also be the main way of regional electricity supply and coal-fired power plants pour a large volume of pollutants to the atmosphere, for example, $\mathrm{SO}_{2}$ and $\mathrm{NO}_{x}$, while generating energy. It is a top priority of environment protection to bring emission of $\mathrm{SO}_{2}$ and $\mathrm{NO}_{x}$ under control.

In order to analyze the influence of external environmental policies, we set the manager's risk attitude at some certain level (i.e., $\lambda=0.85$ ) and compare the results. Figure 3 illustrates the generation strategies for conventional technologies under different emission reduction goals with $\lambda=0.85$. The electricity supply structure has no change until emission reduction targets is higher than $30 \%$. Although coal-fired generation would be still at domination, the stricter environmental policy would fascinate the clean energy utilization during the planning horizon. For example, during period 1 , with high load demand expectation and the loosest environmental policy ( $0 \%$ reduction goal), the power generated by coal, natural gas, hydropower, wind, and solar power would be $[412.00,429.00] \times 10^{3} \mathrm{GWh}, 30.00 \times$ $10^{3} \mathrm{GWh},[47.83,50.83] \times 10^{3} \mathrm{GWh}, 25.18 \times 10^{3} \mathrm{GWh}$, and $5.00 \times 10^{3} \mathrm{GWh}$, respectively. Under the same condition, with the tightest environmental policy ( $30 \%$ reduction goal), the coal-fired power generation would decrease to $409.28 \times$ $10^{3} \mathrm{GWh}$, the natural gas-fired generation would increase to $[47.83,50.83] \times 10^{3} \mathrm{GWh}$, and the performance of wind power and solar power would stay at the same values. Besides, the renewable energy generation would have a higher penetration in the future. For example, under the medium load demand prediction and $20 \%$ reduction goal, the wind power generation would be $25.18 \times 10^{3} \mathrm{GWh}, 27.83 \times 10^{3} \mathrm{GWh}$, and $28.49 \times 10^{3} \mathrm{GWh}$ during periods 1 to 3 , respectively.

Figure 4 shows the pollutions-emission amount under different emission reduction goals when $\lambda$ is fixed as 0.85 . As expected, tighter environmental policy leads to stricter pollution control. During period 3, with $0 \%$ reduction goal and medium load demand prediction, the emissions of $\mathrm{SO}_{2}, \mathrm{NO}_{x}$, and PM would be $[445.75,470.70] \times 10^{3}$ tonne, $[603.30,623.70] \times 10^{3}$ tonne, and $[15.11,22.08] \times 10^{3}$ tonne. When reduction goal rises to $30 \%$, the corresponding emissions would reduce to $[303.23,336] \times 10^{3}$ tonne, $436.59 \times 10^{3}$ tonne, and $[9.59,15.74] \times 10^{3}$ tonne, respectively. However, when the pollutants mitigation level is below $30 \%$, the power generation of different technologies and the amount of pollutants emission would have no change, especially for coal-fired power (as shown in Figures 3 and 4). It indicated that the pollution emission reduction would be mainly through the further application of pollution treatment technologies (e.g., project reduction) and the electric-power system structure adjustment (e.g., structure reduction) in the region would be supplemented in order to reduce the pollutants discharge, when the reduction goal level is under 30\% during the whole planning horizon. In comparison, when the pollutants mitigation level is equal to or greater than $30 \%$, the capacity of project reduction would reach to their upper bound and the structure reduction would begin implementing by enlarging 


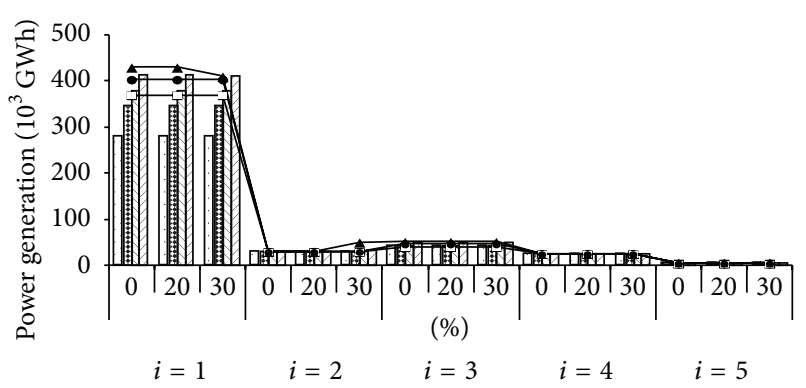

(a)

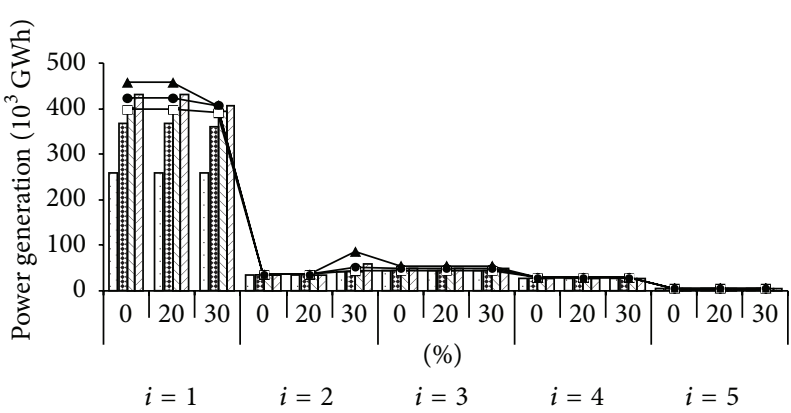

(b)

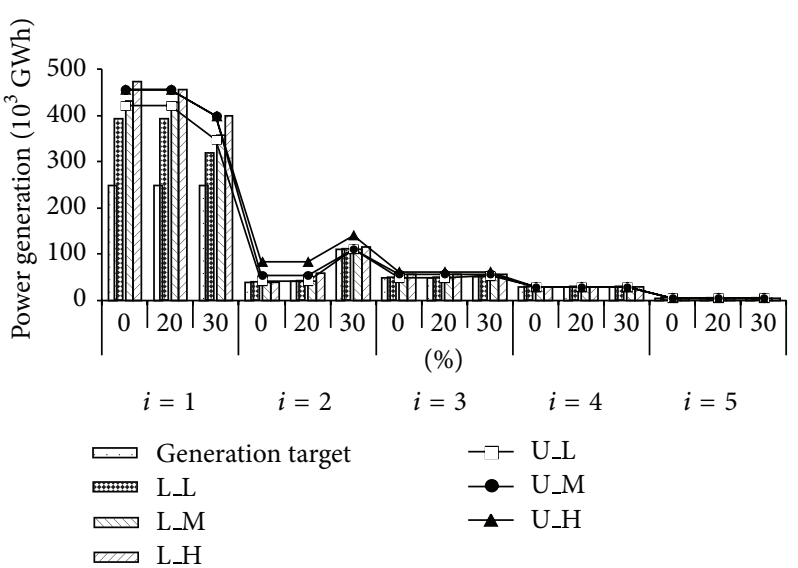

(c)

FIGURE 3: Generation strategies under different emission reduction targets with $\lambda=0.85$. (L_L, L_M, L_H denotes the lower bound solution of low, medium, and high demand level, and U_L, U_M, U_H denotes the upper bound solution of low, medium, and high demand level).

ratio of clean energy utilization and reducing total quantity of coal consumption. The main explanation for these results in Figures 3 and 4 is that the capacity expansion and operation cost of renewable energy generation is much higher than the cost of pollution control. Besides, it is hard to change the energy structure with the domination of coal-fired power in short term. As a result, pollution control devices are the main contributor for pollution treatment. With the higher requirement of emission reduction, the treatment capabilities of pollution control devices reach their maximum limits and the adjustment of generation structure begins to take effect on the regional air quality improvement.

Moreover, the solutions under different risk-aversion levels (downside risk levels) of the managers or decision-makers with the certain external environmental policy are discussed as follows. Figures 5 and 6 present the optimal generation strategies and pollutants-emission amount with $30 \%$ reduction goal, respectively. Under the loose environmental regulatory policy (lower than $30 \%$ reduction goal), the acceptable expected risk has no impact on the optimal solution of the model. Thus, the decision-maker could improve the expected income under the pollutants mitigation level below 30\%. In Figure 5, the results indicated that during periods 1 and 2, the risk-aversion level changes have no influence on the generation structure. However, during period 3, as the downside risk level increasing, the electricity generated by coal-fired power would have a decrease trend and the natural gas fired power and hydropower generation would increase, especially under the low power demand level. In detail, with low demand level, the coal-fired power generation would be $[362.81,392.81] \times$ $10^{3}$ GWh, [317.37, 347.37] $\times 10^{3} \mathrm{GWh}$, and [319.66, 349.66] $\times$ $10^{3} \mathrm{GWh}$ under the scenarios of $\lambda$ with the values of 0 (e.g., ITSP model), 0.7, and 1.0, respectively. Accordingly, the natural gas power generation would be $70.44 \times 10^{3} \mathrm{GWh}$, $112.21 \times 10^{3} \mathrm{GWh}$, and $110.89 \times 10^{3} \mathrm{GWh}$ under the three scenarios, and the hydropower generation would be $48.26 \times$ $10^{3} \mathrm{GWh}, 51.93 \times 10^{3} \mathrm{GWh}$, and $50.96 \times 10^{3} \mathrm{GWh}$, when the $\lambda$ values are fixed as $0,0.7$, and 1.0 , respectively. It indicated that when the pollutants reduction level is equal to or greater than $30 \%$, the power generation schemes would change as $\lambda$ value increases, and the constraints of expected risk and expected income have effect on limiting the unbalance development among different power generation technologies. Figure 6 provides an illustration of pollutants emission amount under different risk-aversion decisions. Under the high demand level, the amount of $\mathrm{SO}_{2}, \mathrm{NO}_{x}$, and PM emission would have no change as the $\lambda$ value increases. In general, under the low demand level, the emission amount of the pollutants would have slight decrease trends. For $\mathrm{SO}_{2}$, the total emission amount would be $336.00 \times 10^{3}$ tonne and $[310.99,324.53] \times$ $10^{3}$ tonne under $\lambda$ with the values 0 and 1.0 in period 3 ; the total amount of $\mathrm{NO}_{x}$ emission would be $436.59 \times 10^{3}$ tonne 


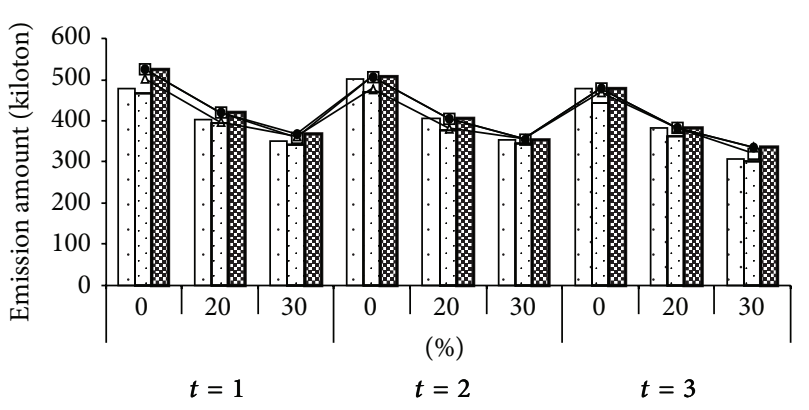

(a)

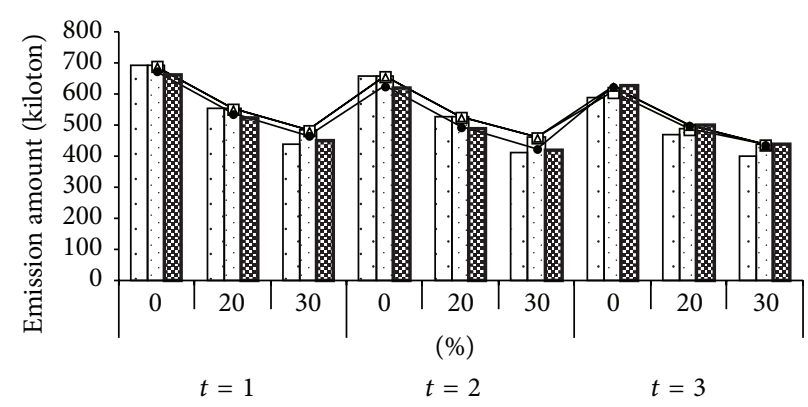

(b)

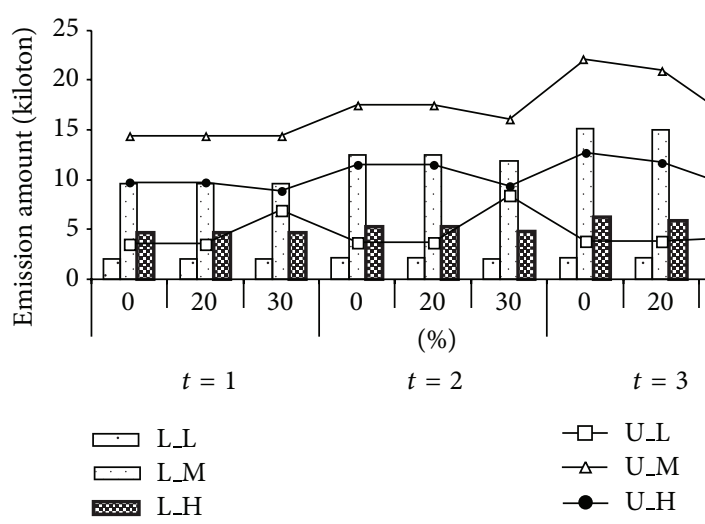

(c)

FIGURE 4: Pollutants emission amount under different mitigation targets with $\lambda=0.85$.

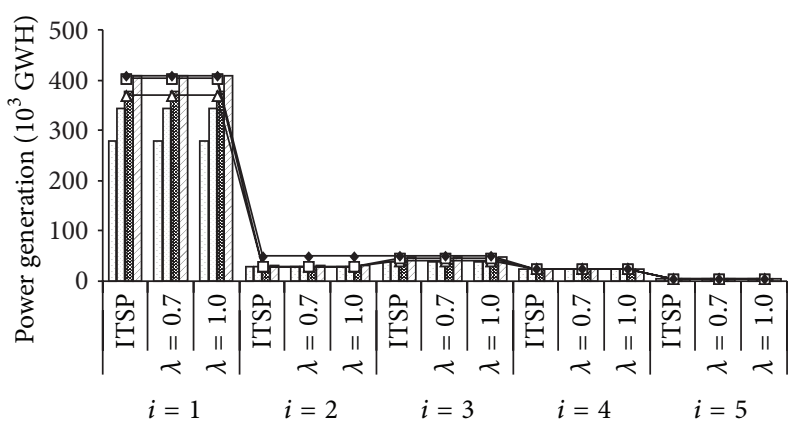

(a)

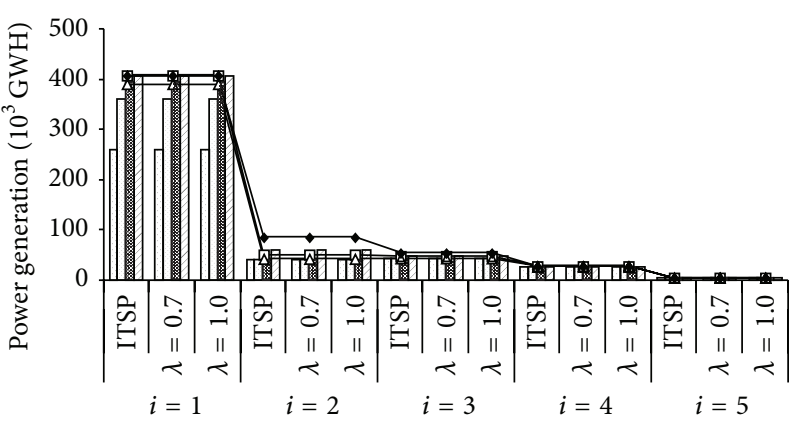

(b)
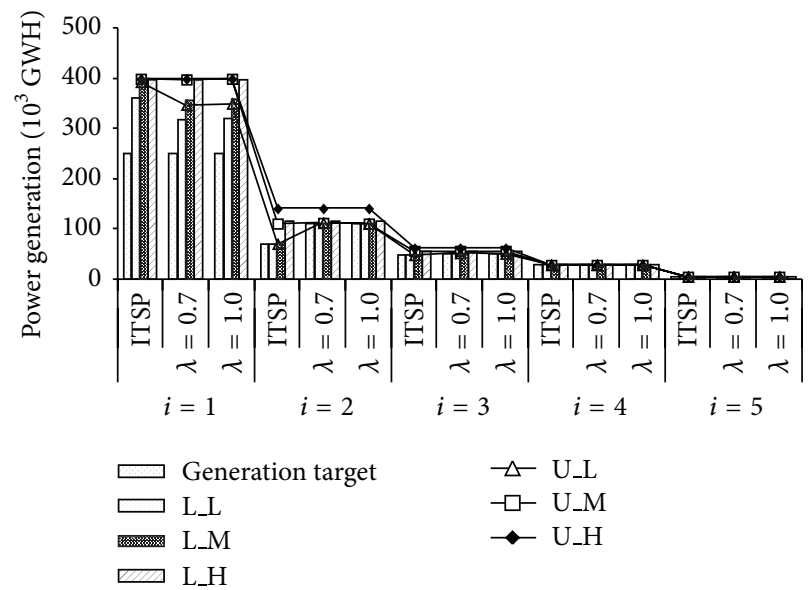

(c)

Figure 5: Generation strategies with 30\% mitigation goal under different risk levels. 


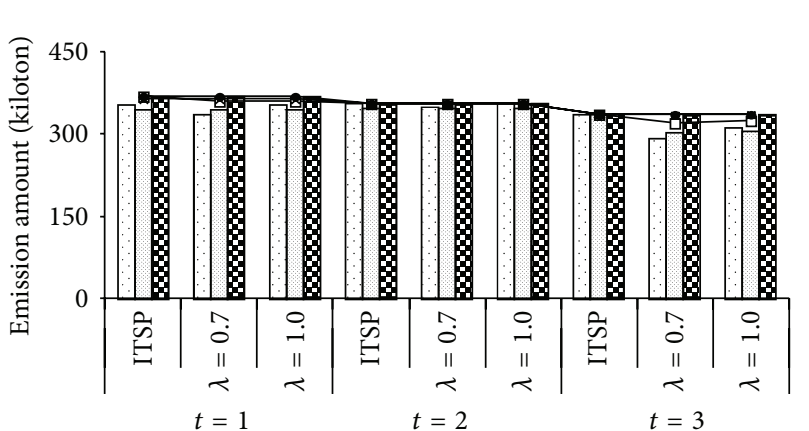

(a)

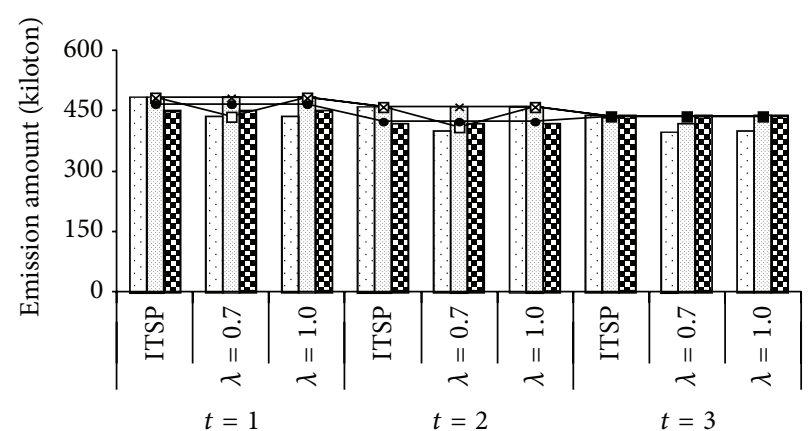

(b)

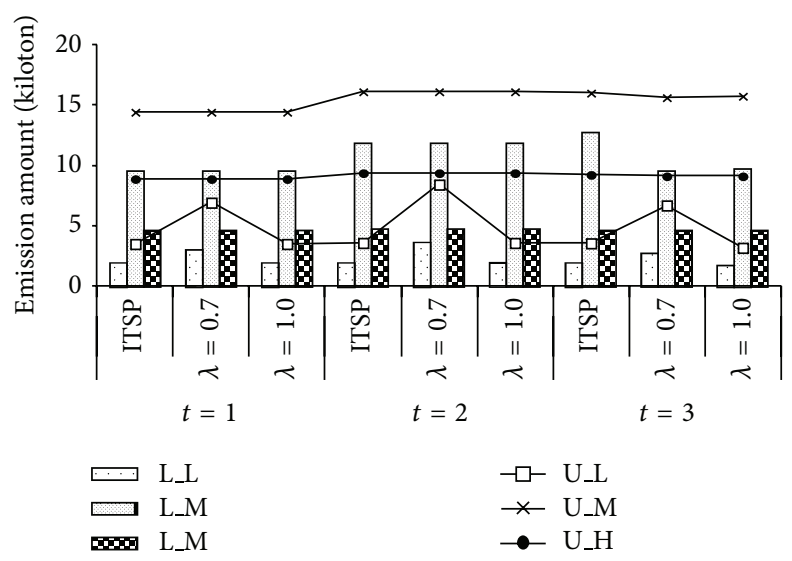

(c)

Figure 6: Pollutants emission amount with 30\% mitigation goal under different risk levels.

and $[398.11,436.59] \times 10^{3}$ tonne; and for PM, the emission amount would be $[1.99,3.58] \times 10^{3}$ tonne and $[1.78,3.22] \times 10^{3}$ tonne when the $\lambda$ values are fixed as 0 and 1.0. Generally, as $\lambda$ value increases, the power generated by the technology with lower cost and higher air pollution-emission rate would decrease, and the amount of renewable power generation with low pollution-emission rate would increase. In such a case, the extreme risk could be lowered and the system feasibility could be enhanced.

From the above analysis, it is indicated that the effect of the risk measure on the modeling outputs could be adjusted by changing $\lambda$ value. Figure 7 shows the model's optimal net benefits under various emission reduction scenarios and risk-aversion levels. As expected, stricter environmental regulatory policy would cause higher system costs and result in lower net benefits. For example, the optimal objective net benefits in ITSP model would be [3738.43, 12900.93], $[3470.59,12411.13]$, and $[2170.89,10355.95] \times 10^{6} \$$, when the pollutants emission reduction goal is $0 \%, 20 \%$, and $30 \%$, respectively. This implies that, when environmental constraints are added, high-efficiency mitigation measures/renewable power projects must be installed to reduce the pollutant emissions and to satisfy the environmental requirements and that would lead to a higher cost for the regional electric-power system. Besides, higher riskaversion level would lead to a lower objective net benefit. The net benefits would be $[1474.95,10295.88] \times 10^{6} \$$,
$[1492.57,10315.37] \times 10^{6} \$$, and $[1531.60,10323.63] \times 10^{6} \$$ with the value of $\lambda$ as $0.70,0.85$, and 1.00 under $30 \%$ emission reduction goal, respectively. It indicated that a lower $\alpha$ value would result in a higher possibility of system loss in extreme conditions. Moreover, with the introduction of downside risk aversion, it restricts expressivity of the power generation technology with higher income and reduces the downside risk of failing to reach an income target as much as possible.

\section{Conclusion}

In this paper, an inexact two-stage stochastic programming model combined with downside risk theory is developed to deal with the long-term electricity system programming. In the framework of inexact two-stage stochastic programming, the uncertainties are allowed to be expressed as interval numbers. The results help the decision-maker to arrange investment plan including capacity expansion and pollution control devices with the aim of maximum total profits and also assist in providing optimal operation strategy. The downside risk allows providing the proper trade-off strategy between the maximum profit and minimum risk with the consideration of the decision-maker's risk-aversion levels. The capability of this approach is verified through its application on the electricity system in Ningxia, China. The results indicate that pollution control devices are still the main measures to achieve the current mitigation goal, and 


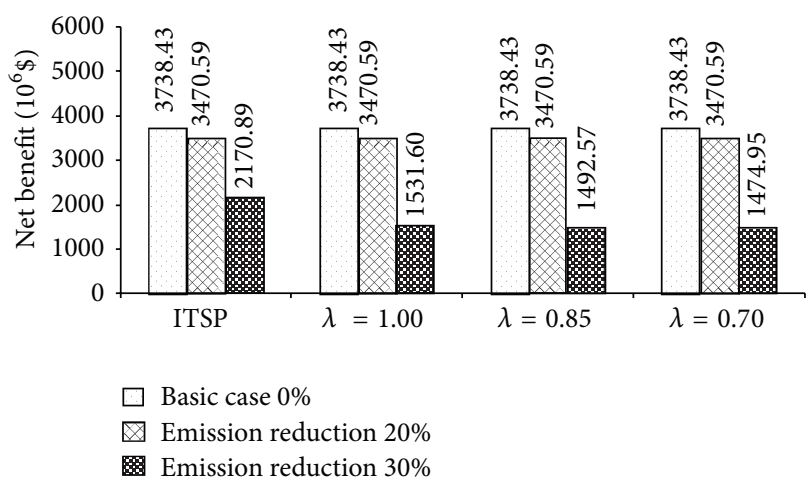

(a)

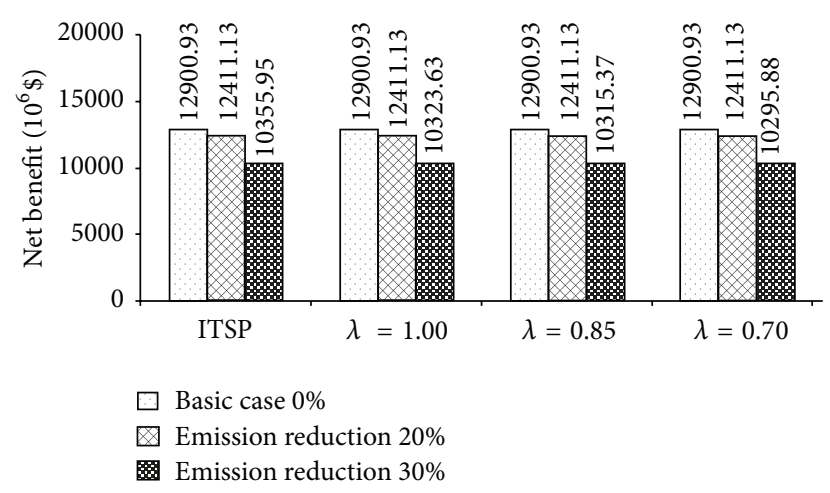

(b)

FIGURE 7: Objective benefits under different scenarios.

with the stricter environmental policy, the adjustment of generation structure would play an important role in the future cleaner electricity system. The presented approach would be applied to other energy system programming and handle the risk management problem when facing various uncertainties. In future research, more flexible market machine (e.g., $\mathrm{CO}_{2}$ trading machine) should be considered in the long-term electricity system programming.

\section{Conflict of Interests}

The authors declare that there is no conflict of interests regarding the publication of this paper.

\section{Acknowledgments}

This work was financially supported by China Scholarship Council (CSC) and NSFC under Grant no. 71071052 as well as the Fundamental Research Funds for the Central Universities under Grants nos. 12QX23 and 13XS20. The authors are grateful to the anonymous reviewers and editors for their valuable comments and suggestions.

\section{References}

[1] M. Zhang, X. Liu, W. Wang, and M. Zhou, "Decomposition analysis of $\mathrm{CO}_{2}$ emissions from electricity generation in China," Energy Policy, vol. 52, pp. 159-165, 2013.

[2] M. A. Al-Mayyahi, A. F. A. Hoadley, and G. P. Rangaiah, "A novel graphical approach to target $\mathrm{CO}_{2}$ emissions for energy resource planning and utility system optimization," Applied Energy, vol. 104, pp. 783-790, 2013.

[3] H. M. I. Pousinho, V. M. F. Mendes, and J. P. S. Catalão, "A risk-averse optimization model for trading wind energy in a market environment under uncertainty," Energy, vol. 36, no. 8, pp. 4935-4942, 2011.

[4] D. Buoro, M. Casisi, A. De Nardi, P. Pinamonti, and M. Reini, "Multicriteria optimization of a distributed energy supply system for an industrial area," Energy, vol. 58, pp. 128-137, 2013.

[5] Y. Tohidi, F. Aminifar, and M. Fotuhi-Firuzabad, "Generation expansion and retirement planning based on the stochastic programming," Electric Power Systems Research, vol. 104, pp. 138-145, 2013.

[6] A. L. Yang, G. H. Huang, Y. R. Fan, and X. D. Zhang, "A fuzzy simulation-based optimization approach for groundwater remediation design at contaminated aquifers," Mathematical Problems in Engineering, vol. 2012, Article ID 986867, 13 pages, 2012.

[7] W. T. Chen, Y. P. Li, G. H. Huang, X. Chen, and Y. F. Li, "A two-stage inexact-stochastic programming model for planning carbon dioxide emission trading under uncertainty," Applied Energy, vol. 87, no. 3, pp. 1033-1047, 2010.

[8] M. W. Li, Y. P. Li, and G. H. Huang, "An interval-fuzzy two-stage stochastic programming model for planning carbon dioxide trading under uncertainty," Energy, vol. 36, no. 9, pp. 5677-5689, 2011.

[9] S. Mirkhani and Y. Saboohi, "Stochastic modeling of the energy supply system with uncertain fuel price-a case of emerging technologies for distributed power generation," Applied Energy, vol. 93, pp. 668-674, 2012.

[10] P. Jirutitijaroen, S. Kim, O. Kittithreerapronchai, and J. Prina, "An optimization model for natural gas supply portfolios of a power generation company," Applied Energy, vol. 107, pp. 1-9, 2013.

[11] Y. Xu and X. S. Qin, "Agricultural effluent control under uncertainty: an inexact double-sided fuzzy chance-constrained model," Advances in Water Resources, vol. 33, no. 9, pp. 997-1014, 2010.

[12] P. Guo, G. H. Huang, L. He, and Y. P. Cai, "ICCSIP: an inexact chance-constrained semi-infinite programming approach for energy systems planning under uncertainty," Energy Sources A, vol. 30, no. 14-15, pp. 1345-1366, 2008.

[13] Y. L. Xie, Y. P. Li, G. H. Huang, and Y. F. Li, "An interval fixed-mix stochastic programming method for greenhouse gas mitigation in energy systems under uncertainty," Energy, vol. 35, no. 12, pp. 4627-4644, 2010.

[14] Y. P. Li and G. H. Huang, "Electric-power systems planning and greenhouse-gas emission management under uncertainty," Energy Conversion and Management, vol. 57, pp. 173-182, 2012.

[15] C. Dong, G. H. Huang, Y. P. Cai, and Y. Liu, "Robust planning of energy management systems with environmental and constraint-conservative considerations under multiple uncertainties," Energy Conversion and Management, vol. 65, pp. 471486, 2013. 
[16] Y. P. Cai, G. H. Huang, Z. F. Yang, and Q. Tan, "Identification of optimal strategies for energy management systems planning under multiple uncertainties," Applied Energy, vol. 86, no. 4, pp. 480-495, 2009.

[17] L. Ji, D. X. Niu, and G. H. Huang, "An inexact two-stage stochastic robust programming for residential miro-gird management based on random demand," Energy, vol. 67, pp. 186-199, 2014.

[18] G. C. Li, G. H. Huang, C. Z. Wu, Y. P. Li, Y. M. Chen, and Q. Tan, "TISEM: a two-stage interval-stochastic evacuation management model," Journal of Environmental Informatics, vol. 12, no. 1, pp. 64-74, 2008.

[19] Q. G. Lin, G. H. Huang, B. Bass, and X. S. Qin, "IFTEM: an interval-fuzzy two-stage stochastic optimization model for regional energy systems planning under uncertainty," Energy Policy, vol. 37, no. 3, pp. 868-878, 2009.

[20] X. S. Qin, G. H. Huang, B. Chen, and B. Y. Zhang, "An intervalparameter waste-load-allocation model for river water quality management under uncertainty," Environmental Management, vol. 43, no. 6, pp. 999-1012, 2009.

[21] Y. L. Xie and G. H. Huang, "An optimization model for water resources allocation risk analysis under uncertainty," Journal of Hydroinformatics, 2013.

[22] A. Lorca and J. Prina, "Power portfolio optimization considering locational electricity prices and risk management," Electric Power Systems Research, vol. 109, pp. 80-89, 2014.

[23] L. W. Tauer, “Target MOTAD," American Journal of Agricultural Economics, vol. 65, pp. 606-610, 1983.

[24] E. A. Yeager and M. R. Langemeier, "Economic efficiency and downside risk," Applied Economics, vol. 45, no. 36, pp. 50125020, 2013.

[25] H. M. Ghadikolaei, A. Ahmadi, J. Aghaei, and M. Najafi, "Risk constrained self-scheduling of hydro/wind units for short term electricity markets considering intermittency and uncertainty," Renewable and Sustainable Energy Reviews, vol. 16, no. 7, pp. 4734-4743, 2012.

[26] D. Cumova and D. Nawrocki, "Portfolio optimization in an upside potential and downside risk framework," Journal of Economics and Business, vol. 71, pp. 68-89, 2014.

[27] Y. L. Xie and G. H. Huang, "Development of an inexact two-stage stochastic model with downside risk control for water quality management and decision analysis," Stochastic Environmental Research and Risk Assessment, vol. 28, no. 6, pp. 1555-1575, 2014.

[28] X. Qin, Y. Xu, and J. Su, "Municipal solid waste-flow allocation planning with trapezoidal-shaped fuzzy parameters," Environmental Engineering Science, vol. 28, no. 8, pp. 573-584, 2011.

[29] N. Zhang, Y. P. Li, and W. W. Huang, "An inexact two-stage waterquality management model for supporting sustainable development in arural system," Journal of Environmental Informatics, vol. 24, no. 1, pp. 52-64, 2014.

[30] J. R. Birge and F. V. Louveaux, "A multicut algorithm for two-stage stochastic linear programs," European Journal of Operational Research, vol. 34, no. 3, pp. 384-392, 1988.

[31] G. H. Huang, B. W. Baetz, and G. G. Patry, "An interval linear programming approach for municipal solid waste management planning under uncertainty," Civil Engineering and Environmental Systems, vol. 9, pp. 319-335, 1992.

[32] G. H. Huang, "IPWM: an interval parameter water quality management model," Engineering Optimization, vol. 26, no. 2, pp. 79-103, 1996.
[33] W. Li, Y. P. Li, C. H. Li, and G. H. Huang, "An inexact two-stage water management model for planning agricultural irrigation under uncertainty," Agricultural Water Management, vol. 97, no. 11, pp. 1905-1914, 2010.

[34] J. C. Bean, J. L. Higle, and R. L. Smith, "Capacity expansion under stochastic demands," Operations Research, vol. 40, no. 2, pp. 210-216, 1992.

[35] A. Aseeri and M. J. Bagajewicz, "New measures and procedures to manage financial risk with applications to the planning of gas commercialization in Asia," Computers and Chemical Engineering, vol. 28, no. 12, pp. 2791-2821, 2004. 


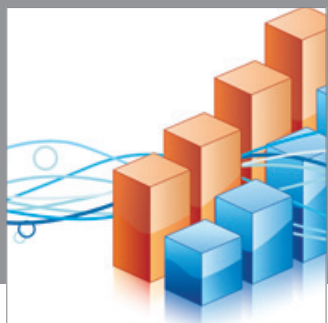

Advances in

Operations Research

mansans

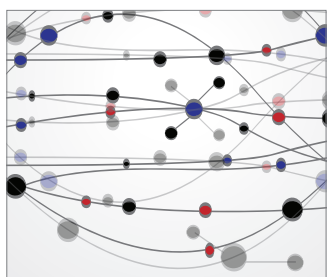

The Scientific World Journal
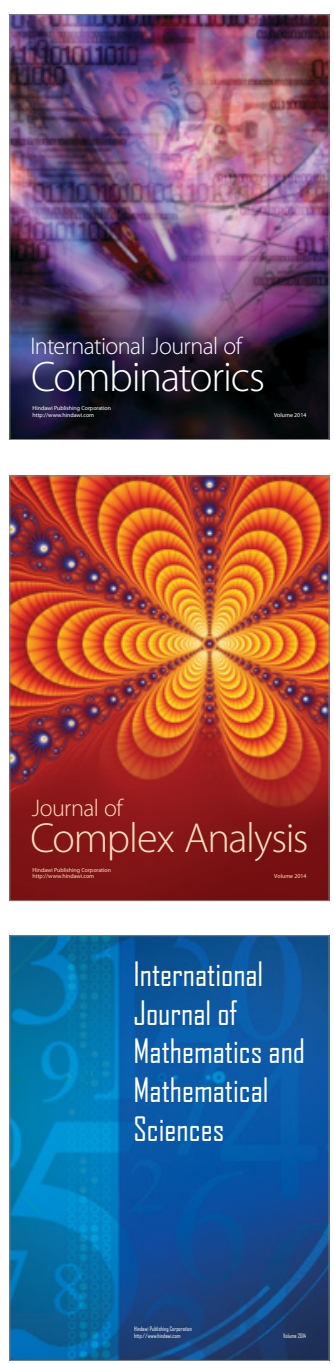
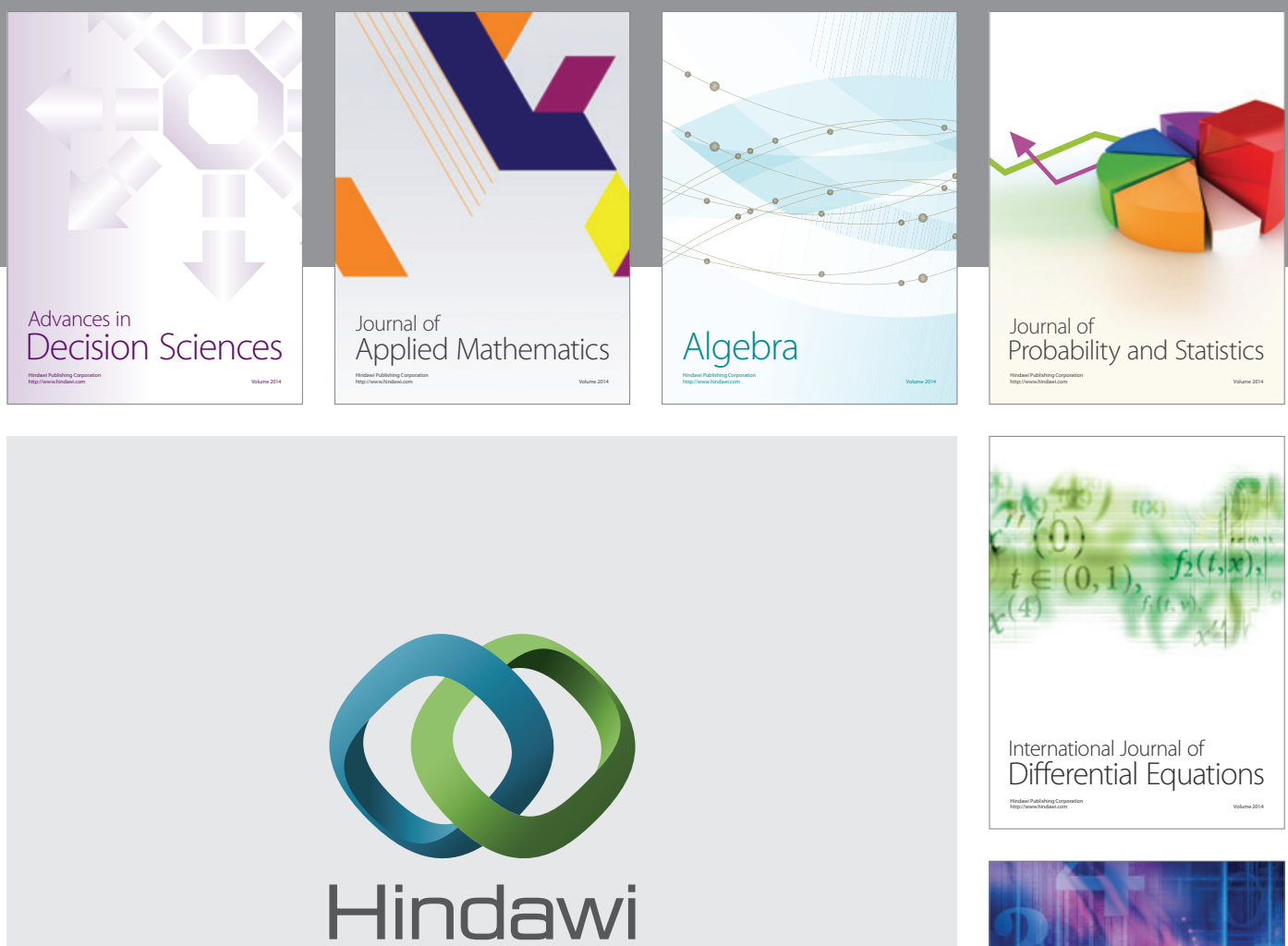

Submit your manuscripts at http://www.hindawi.com
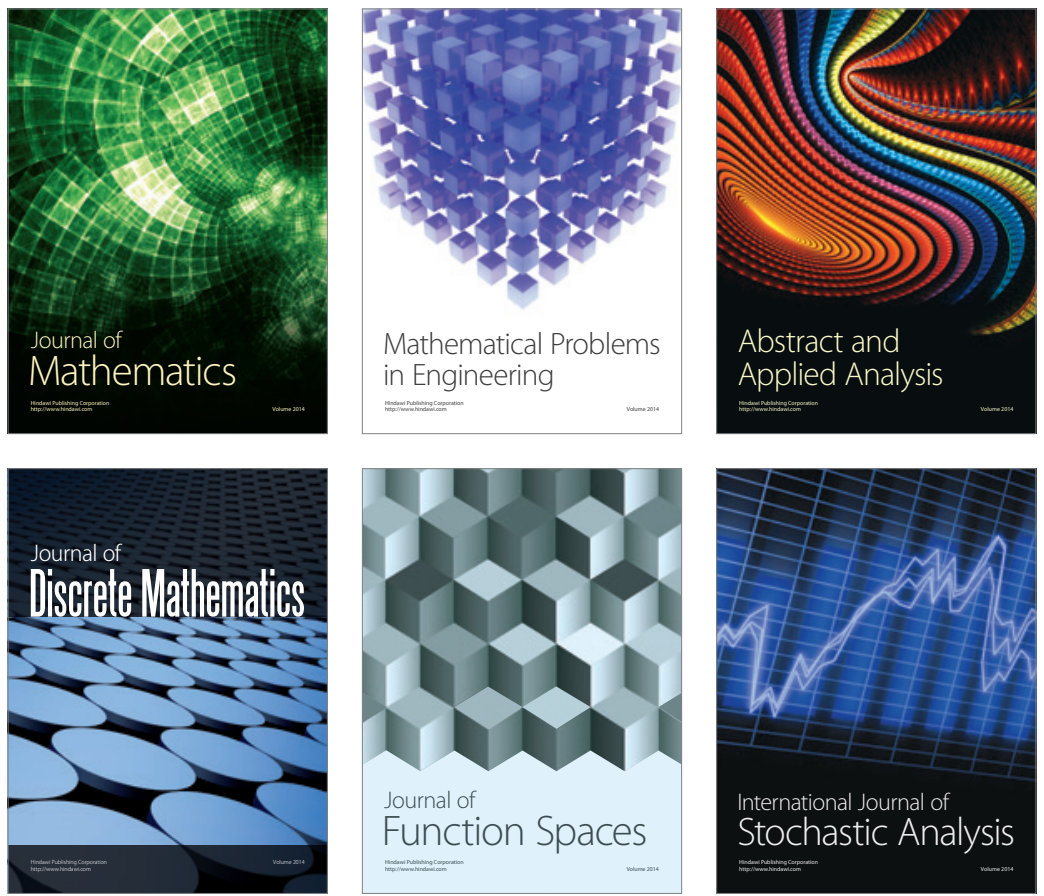

Journal of

Function Spaces

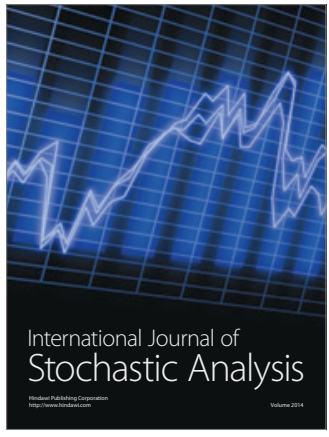

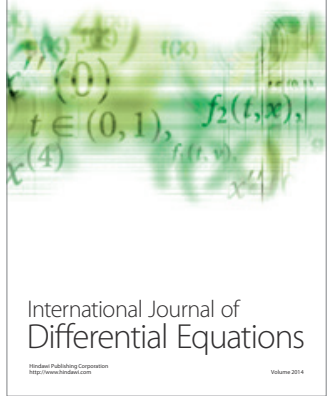
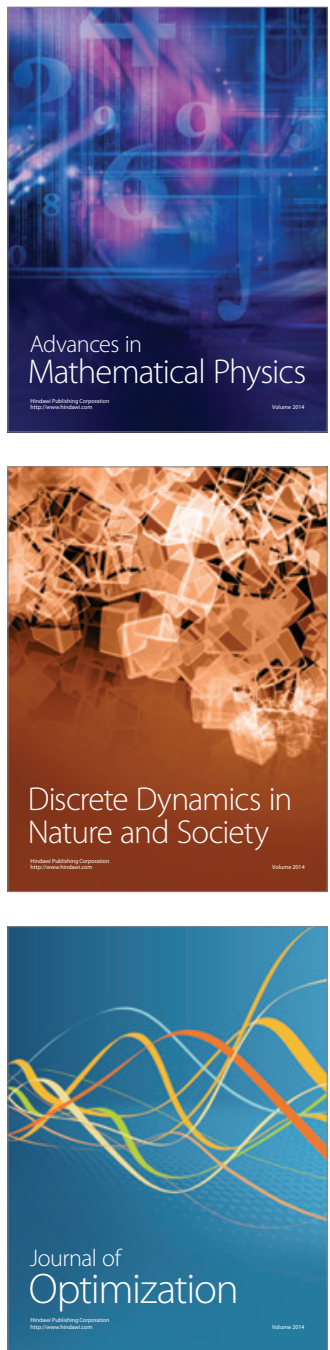